\title{
Face, Notch, or Edge? Intermolecular dissociation energies of 1-naphthol complexes with linear molecules
}

Cite as: J. Chem. Phys. 150, 234303 (2019); https://doi.org/10.1063/1.5100139

Submitted: 15 April 2019 . Accepted: 27 May 2019 . Published Online: 19 June 2019

Richard Knochenmuss (D), Rajeev K. Sinha, and Samuel Leutwyler (iD)

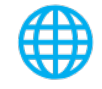

\section{Lock-in Amplifiers up to $600 \mathrm{MHz}$}

starting at $\$ 6,210$

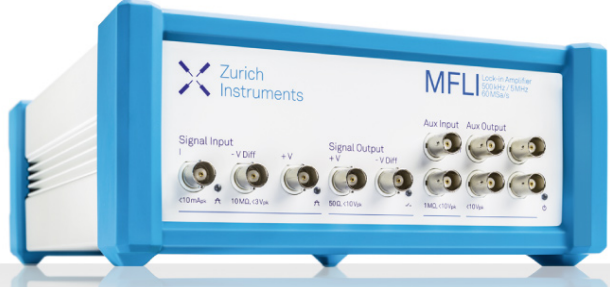

Zurich

Instruments

Watch the Video 


\title{
Face, Notch, or Edge? Intermolecular dissociation energies of 1-naphthol complexes with linear molecules
}

\author{
Cite as: J. Chem. Phys. 150, 234303 (2019); doi: 10.1063/1.5100139 \\ Submitted: 15 April 2019 • Accepted: 27 May 2019 • \\ Published Online: 19 June 2019
}

Richard Knochenmuss, (D) Rajeev K. Sinha, ${ }^{a)}$ and Samuel Leutwyler ${ }^{\mathrm{b}}$

AFFILIATIONS

Department of Chemistry and Biochemistry, University of Bern, Freiestrasse 3, CH-3012 Bern, Switzerland

a) Present address: Department of Atomic and Molecular Physics, Manipal University, Manipal, 576104 Karnataka, India.

b) samuel.leutwyler@dcb.unibe.ch

\begin{abstract}
The stimulated-emission-pumping/resonant 2-photon ionization (SEP-R2PI) method was used to determine the intermolecular dissociation energies $D_{0}$ of jet-cooled 1-naphthol $(1 \mathrm{NpOH}) \cdot \mathrm{S}$ complexes, where $\mathrm{S}$ is a linear molecule $\left(\mathrm{N}_{2}, \mathrm{CO}, \mathrm{CO}_{2}, \mathrm{OCS}, \mathrm{N}_{2} \mathrm{O}\right.$, and ethyne) or symmetrictop molecule (2-butyne) that contains double or triple bonds. The dissociation energies $D_{0}\left(S_{0}\right)$ are bracketed as follows: $6.68 \pm 0.08 \mathrm{~kJ} / \mathrm{mol}$ for $\mathrm{S}=\mathrm{N}_{2}, 7.7 \pm 0.8 \mathrm{~kJ} / \mathrm{mol}$ for $\mathrm{CO}, 12.07 \pm 0.10 \mathrm{~kJ} / \mathrm{mol}$ for $\mathrm{CO}_{2}, 13.03 \pm 0.01 \mathrm{~kJ} / \mathrm{mol}$ for $\mathrm{N}_{2} \mathrm{O}, 14.34 \pm 0.08 \mathrm{~kJ} / \mathrm{mol}$ for ethyne, $15.0 \pm 1.35 \mathrm{~kJ} / \mathrm{mol}$ for OCS, and $29.6 \pm 2.4 \mathrm{~kJ} / \mathrm{mol}$ for 2-butyne. The minimum-energy structures, vibrational wavenumbers, and zero-point vibrational energies were calculated using the dispersion-corrected density functional theory methods such as B97-D3 and B3LYP-D3 with the def2-QZVPP basis set. These predict that $\mathrm{N}_{2}$ and $\mathrm{CO}$ are dispersively bound Face complexes ( $\mathrm{S}$ bound to a naphthalene Face), while $\mathrm{CO}_{2}, \mathrm{~N}_{2} \mathrm{O}$, and $\mathrm{OCS}$ adsorb into the "Notch" between the naphthyl and $\mathrm{OH}$ groups; these are denoted as Notch complexes. Ethyne and 2-butyne form Edge complexes involving $\mathrm{H}$-bonds from the $-\mathrm{OH}$ group of $1 \mathrm{NpOH}$ to the center of the molecule. The presence of a double or triple bond or an aromatic $\mathrm{C}=\mathrm{C}$ bond within $\mathrm{S}$ does not lead to a specific calculated geometry (Face, Notch or Edge). However, a correlation exists between the structure and the sign of the quadrupole moment component $\Theta_{z z}$ of S: negative $\Theta_{z z}$ correlates with Face or Notch, while positive $\Theta_{z z}$ correlates with Edge geometries.
\end{abstract}

Published under license by AIP Publishing. https://doi.org/10.1063/1.5100139

\section{INTRODUCTION}

London dispersion forces arise from long-range electron correlation between atoms and/or molecules. ${ }^{1,2}$ These noncovalent interactions between atomic and molecular systems are always attractive and are ubiquitous in all forms of matter. They contribute importantly to the structures and lattice energies of molecular solids and are involved in phenomena such as enzyme-substrate binding, drug-substrate interactions, and protein folding, so they are of great importance in fields ranging from solid-state physics to chemical biology. ${ }^{3-13}$ While London dispersion energies between first- and second-row closed-shell atoms are fairly weak, ${ }^{1-7}$ in molecular systems, they increase with the number of atoms and dispersive contributions to the intermolecular binding energy may be larger than the electrostatic contributions.
In density-functional theory (DFT), the introduction of dispersion-corrected functionals ${ }^{14-18}$ has proved to be a major advance, since they reduce the need for very challenging highlevel correlated methods, ${ }^{13,19-21}$ which require very large basis sets to accurately capture the intermolecular correlation energy. ${ }^{13}$

However, the parameterization of the dispersion terms employed in DFT-D methods has mainly been based on calculations, and the databases used to benchmark the DFT-D calculations of dispersively bound complexes are themselves mostly based on calculations. $^{22,24,25}$ To ensure that the methods are accurate and can be used with confidence, it is critical that they are benchmarked and corrected by experimental results.

We have recently determined the accurate intermolecular dissociation energies $D_{0}\left(S_{0}\right)$ of complexes of the hydroxyaromatic 1-naphthol $(1 \mathrm{NpOH})$ with solvent molecules $S$, where $S$ is a 
noble-gas atom ( $\mathrm{Ne}, \mathrm{Ar}, \mathrm{Kr}$, and $\mathrm{Xe}$ ) or diatomic $\mathrm{N}_{2}$; these lie in the range $D_{0}=3.4-10.8 \mathrm{~kJ} / \mathrm{mol}^{29}$ These complexes are dispersively bound, with S being adsorbed to one "Face" of the naphthalene moiety and are thus termed Face complexes. We extended these $D_{0}$ measurements to $1 \mathrm{NpOH}$ complexed with nonpolar cycloalkanes, ${ }^{19,30,31}$ and with the $n$-alkanes from methane to $n$-butane. ${ }^{32} 1 \mathrm{NpOH}$ complexes can also form another type of structure denoted as Edge, in which the $\mathrm{OH}$ group of $1 \mathrm{NpOH}$ forms a classical hydrogen bond to $\mathrm{S}$ molecules with lone-pair bearing $\mathrm{N}$ or $\mathrm{O}$ atoms. ${ }^{33-35}$ Nonclassically, H-bonded Edge complexes are formed with dipolar aromatic solvents, such as $\mathrm{S}=$ thiophene, furan, and dimethylfuran, ${ }^{29}$ but also with nonpolar molecules that offer electron-rich $\mathrm{C}-\mathrm{C}$ bonds, such as cyclopropane, ${ }^{19}$ or aromatic double bonds, such as benzene. ${ }^{35,36}$ On the other hand, the triply bonded $\mathrm{N}_{2}$ molecule forms a Face complex. ${ }^{29}$ Thus, while all nonclassically H-bonded Edge molecules contain electron-rich $\mathrm{C}-\mathrm{C}$ or aromatic $\mathrm{C}=\mathrm{C}$ bonds, the presence of double or triple bonds in $\mathrm{S}$ does not guarantee the formation of an Edge complex.

To increase the diversity of species for which accurate experimental $D_{0}\left(S_{0}\right)$ are available, and to further elucidate the factors affecting the bonding of noncovalent complexes, we here report on $1 \mathrm{NpOH}$ complexes with seven linear (or symmetric-top) molecules containing electron-rich double and triple bonds. Specifically, the goals of the present work are (1) to measure the ground-state dissociation energies $D_{0}\left(S_{0}\right)$ of the seven complexes using the stimulatedemission pumping resonant two-photon ionization (SEP-R2PI) method, ${ }^{13,19,29,30,33,36-38}$ (2) to compare polar doubly bonded linear molecules $\left(\mathrm{S}=\mathrm{N}_{2} \mathrm{O}\right.$, OCS $)$ with nonpolar doubly bonded $\mathrm{CO}_{2}$, with nonpolar triply bonded linear molecules $\left[S=\mathrm{N}_{2}\right.$, ethyne (acetylene), and 2-butyne (dimethylacetylene)], and with the weakly polar triply bonded CO, (3) to investigate the correlation of the dissociation energies with the molecular properties of the solvent molecules such as isotropic polarizability $\bar{\alpha}(S)$ and the quadrupole moment components $\Theta_{k k}(S), k=x, y$, or $z$, and (4) to compare the experimental dissociation energies to those calculated by dispersion-corrected DFT methods, in particular, the role of the zero-point vibrational energy (ZPVE) contributions from the intermolecular vibrations that arise between the $1 \mathrm{NpOH}$ and $\mathrm{S}$ moieties, and the change of the intramolecular ZPVE of the two monomer moieties that arise upon complex formation.

\section{METHODS}

\section{A. Experimental}

The $1 \mathrm{NpOH}$ complexes were formed and cooled in supersonic expansions of $0.2 \%-1 \%$ of the solvent molecule which was diluted in $\mathrm{Ne}$ gas ( $99.99 \%$ purity). The gas mixture at a stagnation pressure of 1.2-1.6 bars was passed over the $1 \mathrm{NpOH}$ heated to $340 \mathrm{~K}(0.1 \mathrm{mbar}$ vapor pressure) in the pulsed valve (nozzle diameter $0.4 \mathrm{~mm}$ ). The resulting supersonic jet was skimmed and passed into the source region of a $1.2 \mathrm{~m}$ linear time-of-flight mass spectrometer.

The $S_{0}$ state dissociation energies of the jet-cooled $1 \mathrm{NpOH} \cdot \mathrm{S}$ complexes were determined using vibrational predissociation (VP) in the $S_{0}$ state. High vibrational levels of the ground state complex were populated using stimulated-emission pumping (SEP) ${ }^{39}$ via the $S_{0} \leftrightarrow S_{1}$ transition. Following the pump and dump steps, vibrational predissociation of the hot M.S levels was detected by a third time-delayed laser using resonant two photon ionization (R2PI) at "hot" vibronic transitions that lie close to the $0_{0}^{0}$ band of the $S_{0} \rightarrow S_{1}$ transition. This triply resonant method is abbreviated as SEP-R2PI; ${ }^{13,33,34,36-38}$ a scheme is shown in Fig. S1 (supplementary material). Detailed descriptions of the method have been previously given. ${ }^{19,29-32,35}$

\section{B. Theoretical methods}

The minimum-energy structures and harmonic vibrational frequencies of the $1 \mathrm{NpOH} \cdot \mathrm{S}$ complexes were calculated using three dispersion-corrected density functional methods. The B97-D3 ${ }^{14}$ and B3LYP-D3 ${ }^{27}$ methods were employed with the def2-TZVPP and def2-QZVPP basis sets, using Gaussian $16 .^{40}$ Structural optimizations were unconstrained and were first performed with the triplezeta basis set. Structural optimizations with the def2-QZVPP basis set were then performed for the isomers with lowest TZVPP energy, and these results are reported below; the triple-zeta results are reported in Table T1 (supplementary material). For comparison, we employed the Chai-Gordon long-range and dispersion-corrected $\omega$ B97X-D functional, ${ }^{16}$ as implemented in Gaussian $16,{ }^{40}$ using the $6-311++G(d, p)$ basis set; these results are also reported in Table T1 (supplementary material).

The $S_{0}$ state binding energies $D_{e}\left(S_{0}\right)$ were calculated by subtracting the total energies of 1-naphthol and of S (both optimized at their respective isolated-molecule geometries) from the total energy of the $1 \mathrm{NpOH} \cdot \mathrm{S}$ complex at its optimized minimum-energy geometry. In the $\omega \mathrm{B} 97 \mathrm{X}-\mathrm{D}$ calculations, the basis set superposition error (BSSE) was corrected using the Boys-Bernardi counterpoise (CP) method. With the def2-TZVPP basis set, the BSSE effects start to be negligible, ${ }^{14}$ and with the larger def2-QZVPP basis set employed here, the BSSE effects become so small that CP correction is not recommended; ${ }^{14}$ thus $\mathrm{CP}$ correction was not performed for the def2-QZVPP basis set.

The harmonic frequencies and vibrational zero point energies (VZPEs) of the monomers and complexes were calculated with all three DFT methods at the same level as the optimized structures. The dissociation energies $D_{0}$ were then calculated as $D_{0}=D_{e}-\triangle \mathrm{VZPE}$, using the change in zero-point energies $\triangle \mathrm{VZPE}$, which is given by $\Delta \mathrm{VZPE}=\operatorname{VZPE}(1 \mathrm{NpOH} \cdot \mathrm{S})-\operatorname{VZPE}(1 \mathrm{NpOH})-\operatorname{VZPE}(\mathrm{S})$.

\section{RESULTS}

\section{A. R2PI spectra of 1-naphthol.S complexes}

The one-color resonant two-photon ionization spectra of supersonically cooled $1 \mathrm{NpOH}$ and its complexes with linear molecules are shown in Fig. 1 . The $S_{0} \rightarrow S_{1}$ electronic origins of the complexes are shifted to higher or lower wavenumbers than the $0_{0}^{0}$ band of $1 \mathrm{NpOH}$ (at $31455.9 \mathrm{~cm}^{-1}$ ), see Fig. 1(a). The spectral shift corresponds to the difference of the ground- and excited-state dissociation energies $\delta \tilde{v}=D_{0}\left(S_{0}\right)-D_{0}\left(S_{1}\right) .^{33,36-38,41}$ Thus, a spectral blue shift corresponds to a decrease of the dissociation energy of the $1 \mathrm{NpOH} \cdot \mathrm{S}$ complex upon $S_{0} \rightarrow S_{1}$ excitation. The low-frequency bands toward the high-energy (blue) side of the R2PI spectra in Fig. 1 are assigned to $S_{1}$ state intermolecular vibrational fundamentals, overtones, and combination bands. The R2PI spectra are ordered 
(a) 1-Naphthol

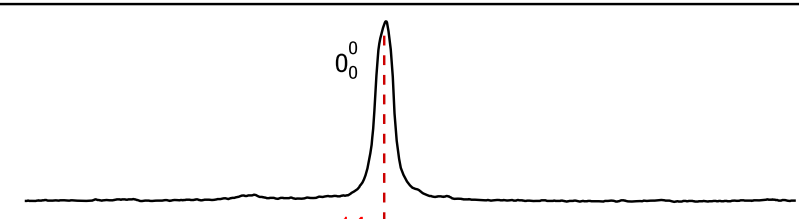

(b) 1-Naphthol• $\mathrm{N}_{2}$

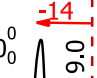<smiles>[Te][Te]</smiles>

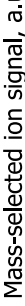

(d) 1-Naphthol• $\mathrm{CO}_{2}$

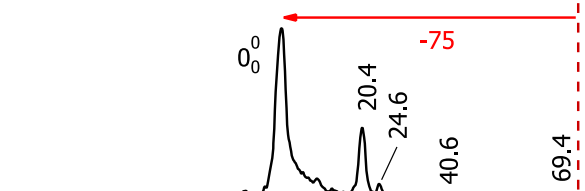

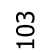

(c) 1-Naphthol•CO

FIG. 1. One-color resonant-two-photon ionization spectra in the $S_{0} \rightarrow S_{1}$ origin region of (a) 1-naphthol and its complexes with (b) $\mathrm{N}_{2}$ (Ref. 29), (c) carbon monoxide, (d) carbon dioxide, (e) dinitrogen oxide, (f) ethyne, $(g)$ carbonyl sulfide, and (h) 2-butyne. The respective $0_{0}^{0}$ bands are at (b) $31442 \mathrm{~cm}^{-1}$, (c) $31381 \mathrm{~cm}^{-1}$, (d) $31476 \mathrm{~cm}^{-1}$, (e) $31493 \mathrm{~cm}^{-1}$, (f) $31352 \mathrm{~cm}^{-1}$, (g) $31383 \mathrm{~cm}^{-1}$, and (h) $31340 \mathrm{~cm}^{-1}$. The spectral shifts $\delta \tilde{v}$ of the $0_{0}^{0}$ bands of the complexes relative to $1 \mathrm{NpOH} 0_{0}^{0}$ band are shown as horizontal arrows. The $S_{1}$ intermolecular vibrational fundamentals are labeled with their wavenumbers; in spectrum (g), a progression in the $11.8 \mathrm{~cm}^{-1}$ vibration is indicated. Intermolecular vibrational assignments are given in Table I.

(g) 1-Naphthol•OCS

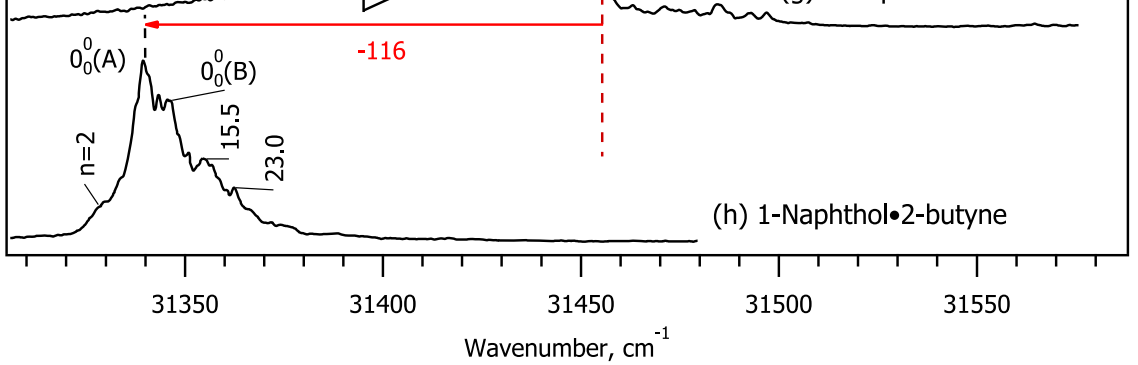

according to the increasing dissociation energy of the complexes, as will be discussed in Sec. III B.

The R2PI spectrum of the $\mathrm{N}_{2}$ complex, see Fig. 1(b), is shifted to the red by $\delta \tilde{v}=-14 \mathrm{~cm}^{-1} .^{29,42}$ Small spectral red shifts, corresponding to small increases of $D_{0}$ upon electronic excitation, are typical for Face complexes of nonpolar S molecules. ${ }^{19,29-32}$ In contrast, the $\mathrm{CO}_{2}$ and $\mathrm{N}_{2} \mathrm{O}$ complexes exhibit significant spectral blue shifts $\left(\delta \tilde{v}=+20 \mathrm{~cm}^{-1}\right.$ and $\left.+38 \mathrm{~cm}^{-1}\right)$, see Figs. $1(\mathrm{~d})$ and 
TABLE I. Experimental and B3LYP-D3/QZVPP calculated intermolecular fundamental frequencies and changes of the vibrational zero-point energies $\triangle V Z P E$ (in $\mathrm{cm}^{-1}$ ) of the 1-naphthol.S complexes with $\mathrm{S}=\mathrm{N}_{2}, \mathrm{CO}, \mathrm{CO}_{2}, \mathrm{~N}_{2} \mathrm{O}, \mathrm{OCS}$, ethyne, and 2-butyne.

\begin{tabular}{|c|c|c|c|c|c|c|c|c|c|c|c|c|c|}
\hline \multirow[b]{2}{*}{ Admolecule } & \multicolumn{5}{|c|}{ Experimental wavenumbers } & \multicolumn{5}{|c|}{ Calculated wavenumbers } & \multicolumn{3}{|c|}{$\Delta$ VZPE (B3LYP-D3 calc.) } \\
\hline & $\tilde{v}_{X}$ & $\tilde{v}_{Y}$ & $\tilde{v}_{Z}$ & $\tilde{v}_{r o t, 1}$ & $\tilde{v}_{r o t, 2}$ & $\tilde{v}_{X}$ & $\tilde{v}_{Y}$ & $\tilde{v}_{Z}$ & $\tilde{v}_{r o t, 1}$ & $\tilde{v}_{r o t, 2}$ & $\Delta_{\text {inter }}$ & $\Delta_{\text {intra }}$ & Total \\
\hline $\mathrm{N}_{2}$ Face & 25.0 & 34.5 & 57 & $\sim 2$ & $\ldots$ & 24.9 & 30.3 & 39.4 & 69.5 & 86.6 & $125.4(87 \%)$ & $18.4(13 \%)$ & 143.8 \\
\hline CO Face & 20.4 & 24.6 & 40.6 & 69.4 & $\ldots$ & 24.7 & 28.2 & 39.9 & 62.9 & 107.8 & $131.8(86 \%)$ & $22.0(14 \%)$ & 153.8 \\
\hline $\mathrm{CO}_{2}$ Notch & $\ldots$ & 26.7 & 43.6 & 55.4 & $\ldots$ & 14.9 & 20.5 & 50.5 & 59.5 & 106.6 & $126.0(65 \%)$ & $67.1(35 \%)$ & 193.1 \\
\hline $\mathrm{N}_{2} \mathrm{O}$ Notch & 13.4 & 20.0 & 45.2 & 81 & $\ldots$ & 17.6 & 26.9 & 52.7 & 72.3 & 109.7 & $139.6(68 \%)$ & $65.2(32 \%)$ & 204.8 \\
\hline OCS Notch & 11.8 & 18.8 & $\ldots$ & 60.6 & 69.5 & 12.8 & 18.2 & 44.6 & 56.1 & 91.3 & $111.5(74 \%)$ & $39.0(26 \%)$ & 150.5 \\
\hline Ethyne Edge & $\ldots$ & 34.6 & 41.5 & 81.2 & $\ldots$ & 12.4 & 31.2 & 40.8 & 80.4 & 83.8 & $124.3(56 \%)$ & $97.2(44 \%)$ & 221.5 \\
\hline 2-butyne Edge & 15.5 & 23.0 & $\ldots$ & $\ldots$ & $\ldots$ & 13.2 & 20.3 & 54.9 & 57.8 & 82.8 & $114.5(37 \%)$ & $195.6(63 \%)$ & 310.1 \\
\hline
\end{tabular}

$1(\mathrm{e})$. Among the approximately 35 complexes of $1 \mathrm{NpOH}$ reported in this and previous work, ${ }^{19,29-32,35}$ these are the first observations of sizable blue shifts. In the sole prior example, the $0_{0}^{0}$ band of the Face isomer of $1 \mathrm{NpOH} \cdot$ cyclopropane is blue shifted by only $+2 \mathrm{~cm}^{-1}$. 19,30 The remaining four complexes investigated here show sizable red shifts, ranging from $-72 \mathrm{~cm}^{-1}$ for OCS to $-116 \mathrm{~cm}^{-1}$ for 2-butyne. Red shifts of similar magnitude have been observed for $1 \mathrm{NpOH} \cdot \mathrm{S}$ complexes, in which $\mathrm{S}$ is nonclassically $\mathrm{H}$-bonded to the 1-naphthol $\mathrm{OH}$ group (Edge geometry), e.g., for $\mathrm{S}=$ benzene $\left(\delta \tilde{v}=-66 \mathrm{~cm}^{-1}\right)$, thiophene $\left(-69 \mathrm{~cm}^{-1}\right)$, the Edge isomer of the cyclopropane complex $\left(-72 \mathrm{~cm}^{-1}\right)$, furan $\left(-81 \mathrm{~cm}^{-1}\right)$, and 2,5-dimethylfuran $\left(-93 \mathrm{~cm}^{-1}\right)$. $^{3 .}$

As is typical for many of the previously investigated complexes, the $\mathrm{CO}, \mathrm{CO}_{2}$, and $\mathrm{N}_{2} \mathrm{O}$ spectra in Fig. 1 exhibit intermolecular vibronic bands, typically with short progressions. Table I lists the observed intermolecular vibrational fundamentals and suggests correlations with the calculated values. The rather intense lowfrequency bands of $1 \mathrm{NpOH} \cdot \mathrm{N}_{2}$ have been explained as internalrotation excitations of a Face structure. ${ }^{29}$ The $1 \mathrm{NpOH} \cdot \mathrm{OCS}$ spectrum exhibits similarly strong excitations in at least two lowfrequency intermolecular vibrations. This suggests that the OCS complex is also a Face structure that exhibits internal-rotation excitations upon $S_{0} \rightarrow S_{1}$ excitation. The 2-butyne complex also shows relatively strong low-wavenumber vibronic bands which could not be fully resolved.

All complexes were investigated by UV/UV hole burning, as shown in Figs. S2-S6 (supplementary material). For the $1 \mathrm{NpOH} \cdot \mathrm{N}_{2}$ complex, we have reported the existence of two isomers. ${ }^{29}$ The more intense isomer 1 spectrum is shown in Fig. 1(b). For the complexes with $\mathrm{S}=\mathrm{CO}, \mathrm{CO}_{2}$, and ethyne, the sharp vibronic bands in the respective R2PI spectra belong to single ground-state isomers. As examples, we show the UV/UV hole-burning spectra of the CO and ethyne complexes in Figs. S2 and S3 (supplementary material). The $1 \mathrm{NpOH} \cdot \mathrm{N}_{2} \mathrm{O}$ complex exhibits a weakly populated second isomer denoted as B, see Fig. 1(e). Its electronic origin is slightly less blue shifted $\left(\delta \tilde{v}=-30 \mathrm{~cm}^{-1}\right)$ than that of the main isomer, which we denote as isomer A. The respective UV/UV hole-burning spectra are shown in Fig. S4 (supplementary material).

For the OCS complex, we compare the R2PI spectrum in Fig. $1(\mathrm{~g})$ to the UV/UV hole-burned spectra in Fig. S5 (supplementary material) where we have hole burned at $0_{0}^{0}+24 \mathrm{~cm}$. The hole-burned spectrum is similar to the R2PI, although some of

TABLE II. Experimental ground- and excited-state dissociation energies $D_{0}\left(S_{0}\right), D_{0}\left(S_{1}\right)$, and spectral shifts of the $0_{0}^{0}$ bands $\delta \tilde{v}$ of the 1-naphthol.S complexes with $\mathrm{S}=\mathrm{N}_{2}, \mathrm{CO}, \mathrm{CO}_{2}, \mathrm{~N}_{2} \mathrm{O}$, OCS, ethyne, and 2-butyne. The $D_{0}$ may lie anywhere within the bracketed intervals with equal probability.

\begin{tabular}{|c|c|c|c|c|c|c|}
\hline \multirow[b]{2}{*}{ Admolecule S } & \multicolumn{2}{|c|}{$D_{0}\left(S_{0}\right)$} & \multicolumn{2}{|c|}{$D_{0}\left(S_{1}\right)$} & \multirow[b]{2}{*}{$\delta \tilde{v}^{\mathrm{a}}\left(\mathrm{cm}^{-1}\right)$} & \multirow[b]{2}{*}{$\%$ change } \\
\hline & $\mathrm{cm}^{-1}$ & $\mathrm{~kJ} / \mathrm{mol}$ & $\mathrm{cm}^{-1}$ & $\mathrm{~kJ} / \mathrm{mol}$ & & \\
\hline $\mathrm{N}_{2}$ (isom. 1) & $565 \pm 7$ & $6.68 \pm 0.08$ & $579 \pm 7$ & $6.93 \pm 0.08$ & -14.4 & +2.5 \\
\hline $\mathrm{CO}$ & $642 \pm 70$ & $7.68 \pm 0.84$ & $712 \pm 70$ & $8.52 \pm 0.84$ & -75 & +11.6 \\
\hline $\mathrm{CO}_{2}$ & $1008 \pm 9$ & $12.07 \pm 0.10$ & $988 \pm 10$ & $11.82 \pm 0.12$ & +20 & -2.0 \\
\hline $\mathrm{N}_{2} \mathrm{O}$ & $1089 \pm 1$ & $13.03 \pm 0.01$ & $1051 \pm 2$ & $12.57 \pm 0.02$ & +38 & -3.5 \\
\hline Ethyne & $1199 \pm 7$ & $14.34 \pm 0.08$ & $1302 \pm 8$ & $15.56 \pm 0.1$ & -103 & +8.6 \\
\hline OCS & $1253 \pm 113$ & $14.98 \pm 1.35$ & $1325 \pm 98$ & $15.85 \pm 1.35$ & -72 & +5.7 \\
\hline 2-butyne & $2471 \pm 200$ & $29.56 \pm 2.39$ & $2587 \pm 200$ & $30.95 \pm 2.39$ & -116 & +4.7 \\
\hline
\end{tabular}

${ }^{\text {a }}$ Spectral shift relative to the $0_{0}^{0}$ band of trans-1-naphthol at $31455.9 \mathrm{~cm}^{-1}$.

${ }^{\mathrm{b}}$ Percent change of $D_{0}\left(S_{1}\right)$ relative to that of the ground state. 
the bands differ in relative intensity. Burning on other intermolecular bands gave slightly different intensity patterns. We conclude that one isomer was dominant, although one or more minority isomers may be present. Since we were unable to clearly separate isomers by hole burning, we expect all to have similar structures.

We also attempted to measure the R2PI spectra of the $1 \mathrm{NpOH} \cdot \mathrm{CS}_{2}$ complex, in analogy to the $\mathrm{CO}_{2}$ and OCS complexes. However, despite the high sensitivity of our apparatus, we were not able to observe any signal of $1 \mathrm{NpOH} \cdot \mathrm{CS}_{2}$.

UV hole burning was performed on $1 \mathrm{NpOH} \cdot 2$-butyne at $31340 \mathrm{~cm}^{-1}$ and $31343 \mathrm{~cm}^{-1}$, as shown in Fig. S6 (supplementary material). The resulting difference spectra indicate the presence of two isomers with nearly identical, strongly overlapping spectra. The main isomer is denoted as $\mathrm{A}$, and the less populous isomer at $31343 \mathrm{~cm}^{-1}$ is denoted as isomer $\mathrm{B}$. Because of their strong spectral similarity, they are presumed to be structurally closely related. Since they cannot be separately excited due to overlap, the results reported here apply to the experimental mixture of $\mathrm{A}$ and $\mathrm{B}$.

\section{B. Experimental dissociation energies}

The ground state dissociation energies $D_{0}\left(S_{0}\right)$ of the $1 \mathrm{NpOH} \cdot \mathrm{S}$ complexes are bracketed between two different $S_{0}$ vibrational states that are observed as vibronic bands in the $S_{1} \rightarrow S_{0}$ spectra: The lower limit to $D_{0}\left(S_{0}\right)$ is given by the highest-energy $S_{0}$ state vibrational level that does not undergo vibrational predissociation. This level is observed via the highest-wavenumber $S_{1} \rightarrow S_{0}$ transition in a hot-band probed SEP-R2PI spectrum as described in Sec. II A. The upper limit to $D_{0}$ is given by the next higher energy vibrational level of the $S_{0}$ state complex that lies above the limit to vibrational predissociation (VP). This and further $S_{0}$ state vibrational levels that lie above the $D_{0}$ limit and undergo VP can be observed by spectroscopic methods that operate on a 1-10 ns time scale, (much) shorter than the typical VP time scale. These are (1) dispersed fluorescence spectroscopy, (2) "dump" (ion dip) spectroscopy, or (3) origin-probed SEP-R2PI spectroscopy; these three methods report on the $S_{0}$ state vibrational levels in a similar way. In the following, we will show the spectrum with the highest $\mathrm{S} / \mathrm{N}$ ratio for comparison with the hot-band probed SEP-R2PI spectrum. We discuss the complexes according to increasing dissociation energy. The experimental ground and derived excited state dissociation energies are summarized in Table II.

\section{1-Naphthol. $N_{2}$}

The R2PI spectrum and the dissociation energies of the two isomers of the $1 \mathrm{NpOH} \cdot \mathrm{N}_{2}$ complex have been previously measured and discussed. ${ }^{29}$ Isomer 1 of the $\mathrm{N}_{2}$ complex is shown in Fig. 2 for comparison with the other doubly and triply bonded solvent molecules. The $\mathrm{N}_{2}$ moiety is adsorbed above the naphthalene Face above the center of either of the aromatic rings. Since the two rings are not equivalent, there are two distinguishable Face isomers, with dissociation energies of $D_{0}=6.68 \pm 0.008 \mathrm{~kJ} / \mathrm{mol}$ and $6.62 \pm 0.22 \mathrm{~kJ} / \mathrm{mol}$, respectively. ${ }^{29}$ As in previous work, the fluorescence spectrum has been inverted to aid in the comparison of weak bands.

\section{1-Naphthol.CO}

In Fig. 3(a), we show the hot-band-probed SEP-R2PI spectrum, measured on a broad feature $47 \mathrm{~cm}^{-1}$ above the $0_{0}^{0}$ band. This complex is unusual, but not unique, in that the hot-band structure appears to the blue of the origin, not to the red, see also Fig. S7 (supplementary material). The highest-energy band in this spectrum is at $573 \mathrm{~cm}^{-1}$ relative to the $0_{0}^{0}$ band. Figure $3(\mathrm{~b})$ shows

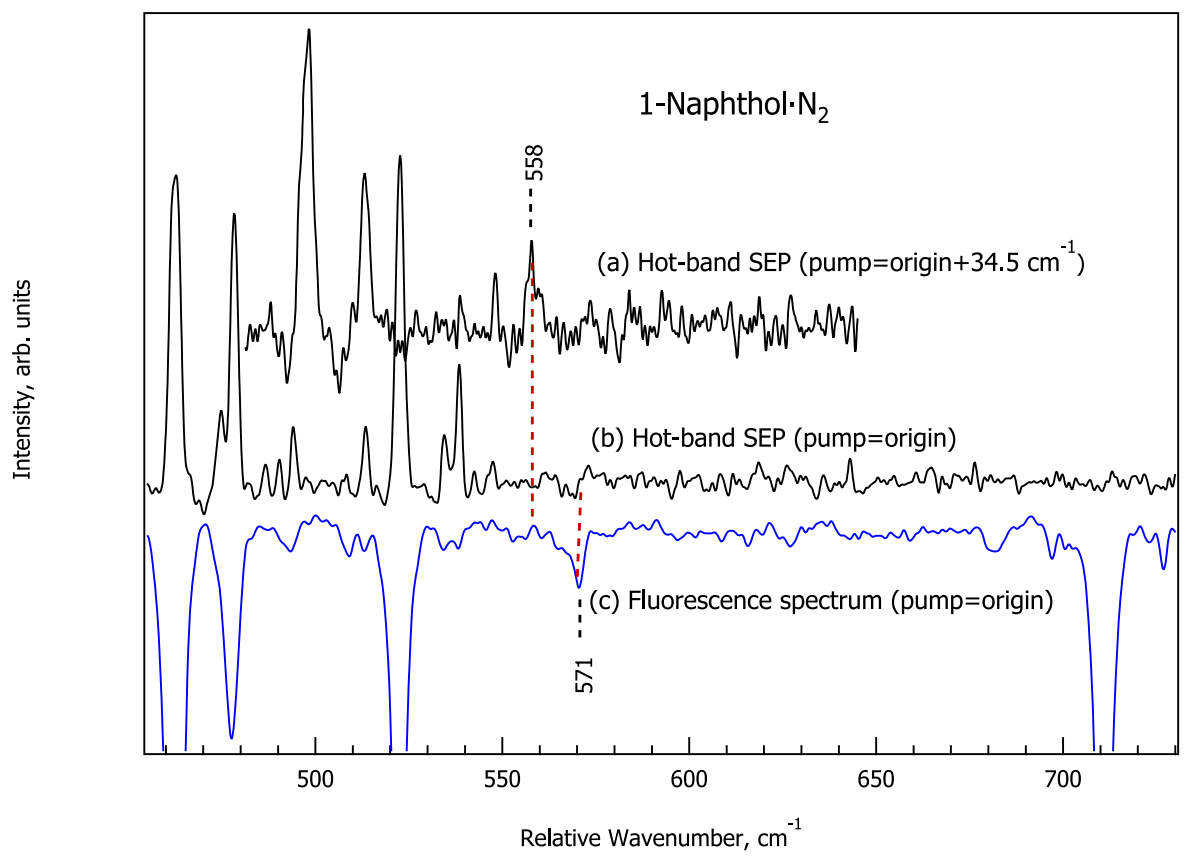

FIG. 2. Hot-band probed SEP-R2PI and inverted fluorescence spectra of isomer 1 of the 1-naphthol. $\mathrm{N}_{2}$ complex, partially taken from Ref. 29. The $x$-axis is the difference between the pump $\left(0_{0}^{0}\right.$ band at $31442 \mathrm{~cm}^{-1}$ or $0_{0}^{0}+34.5 \mathrm{~cm}^{-1}$ ) and the dump laser wavenumbers. The highest-wavenumber transition in (a) at $558 \mathrm{~cm}^{-1}$ marks the lower limit to $D_{0}$, the fluorescence transition in (c) at $571 \mathrm{~cm}^{-1}$ is the upper limit to $D_{0}\left(S_{0}\right)$. 


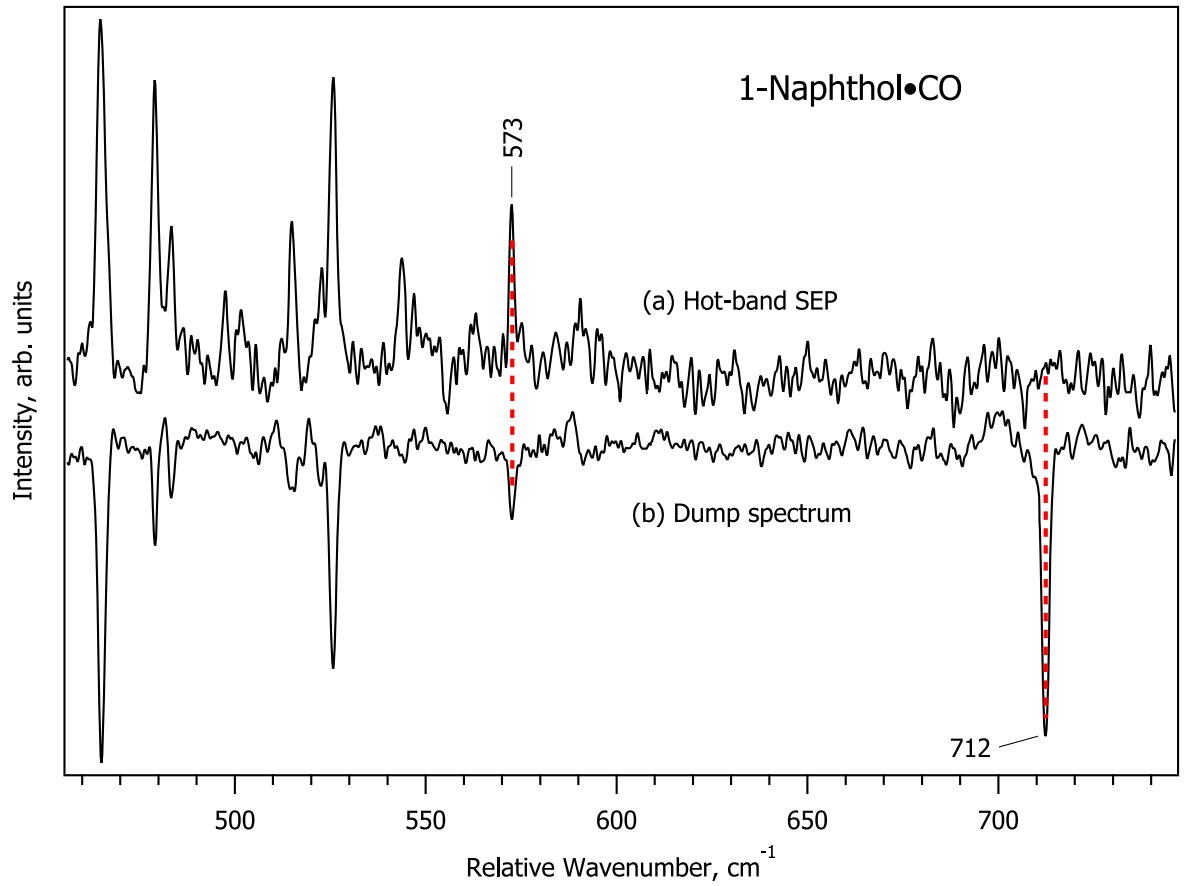

FIG. 3. (a) Hot band $\left(0_{0}^{0}+47 \mathrm{~cm}^{-1}\right)$ probed SEP-R2PI spectrum of $1 \mathrm{NpOH} \cdot \mathrm{CO}$ and (b) the corresponding dump spectrum. The dissociation energy $D_{0}\left(S_{0}\right)$ is bracketed by the vertical red dashed lines at $573 \mathrm{~cm}^{-1}$, the highest-energy band in spectrum (a) and $712 \mathrm{~cm}^{-1}$, the next higher vibronic band in spectrum (b). The horizontal axis is the difference between the pump wavenumber at the $0_{0}^{0}$ band of $1 \mathrm{NpOH} \cdot \mathrm{CO}\left(31381 \mathrm{~cm}^{-1}\right)$ and the dump laser wavenumber. the corresponding dump spectrum, which also exhibits a band at $573 \mathrm{~cm}^{-1}$. The following band in the dump spectrum $3(\mathrm{~b})$ at $712 \mathrm{~cm}^{-1}$ is not observed in trace $3(\mathrm{a})$, nor are any of higherenergy bands; thus it represents the upper limit of $D_{0}\left(S_{0}\right)$. We take the $D_{0}\left(S_{0}\right)$ of $1 \mathrm{NpOH} \cdot \mathrm{CO}$ as the average of the two band positions and the bracketing uncertainty to be half the difference of the two wavenumbers. Thus, $D_{0}\left(S_{0}\right)$ is bracketed to be $642.5 \pm 69.5 \mathrm{~cm}^{-1}$.
Note that the true value may lie anywhere in this range with equal probability.

\section{1-Naphthol. $\mathrm{CO}_{2}$}

Figure 4(a) shows the hot-band-detected SEP spectrum which is probed in the low-wavenumber tail of the hot spectrum, at

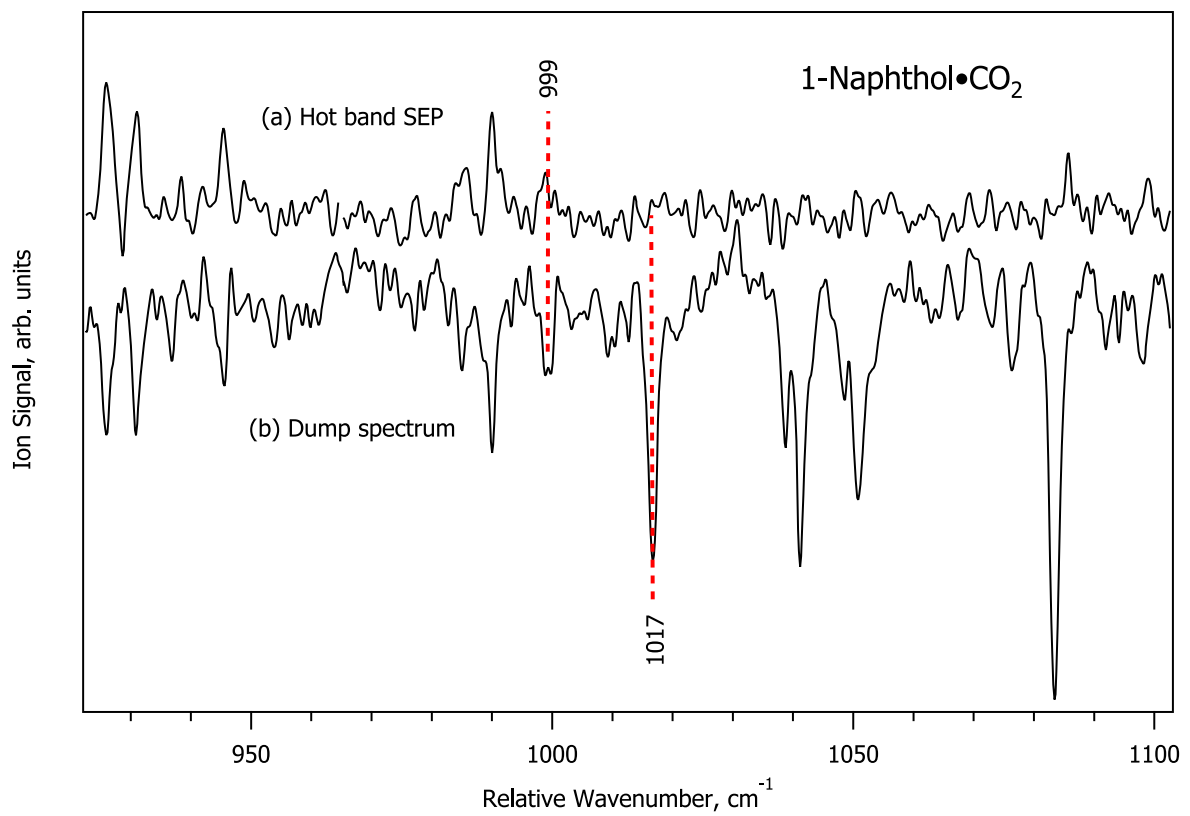

FIG. 4. (a) Hot-band $\left(0_{0}^{0}-111 \mathrm{~cm}^{-1}\right)$ probed SEP-R2PI spectrum of the $1 \mathrm{NpOH} \cdot \mathrm{CO}_{2}$ complex and (b) the corresponding dump spectrum. The horizontal axis is the difference between the pump wavenumber at the $0_{0}^{0}$ band $\left(31475 \mathrm{~cm}^{-1}\right)$ and the dump laser wavenumber. The $D_{0}\left(S_{0}\right)$ is bracketed by the vertical red dashed lines at $999 \mathrm{~cm}^{-1}$ and $1017 \mathrm{~cm}^{-1}$. 
$111 \mathrm{~cm}^{-1}$ below the $0_{0}^{0}$ band, see also Fig. S8 (supplementary material). The highest-wavenumber transition is observed at $999 \mathrm{~cm}^{-1}$. The next unambiguous band in the dump spectrum at $1017 \mathrm{~cm}^{-1}$, Fig. 4(b), is not observed in Fig. 4(a), nor are any of the following bands. Because of the density of vibronic transitions in this spectral region, the $D_{0}\left(S_{0}\right)$ value of the $\mathrm{CO}_{2}$ complex can be bracketed within narrow limits as $D_{0}\left(S_{0}\right)=1008 \pm 9 \mathrm{~cm}^{-1}$.

\section{1-Naphthol. $\mathrm{N}_{2} \mathrm{O}$}

Figure 5 shows two sets of measurements of the $\mathrm{N}_{2} \mathrm{O}$ complex, where we pumped two different bands in the R2PI spectrum in Fig. 1(e). Both give narrow but slightly different $D_{0}$ brackets.

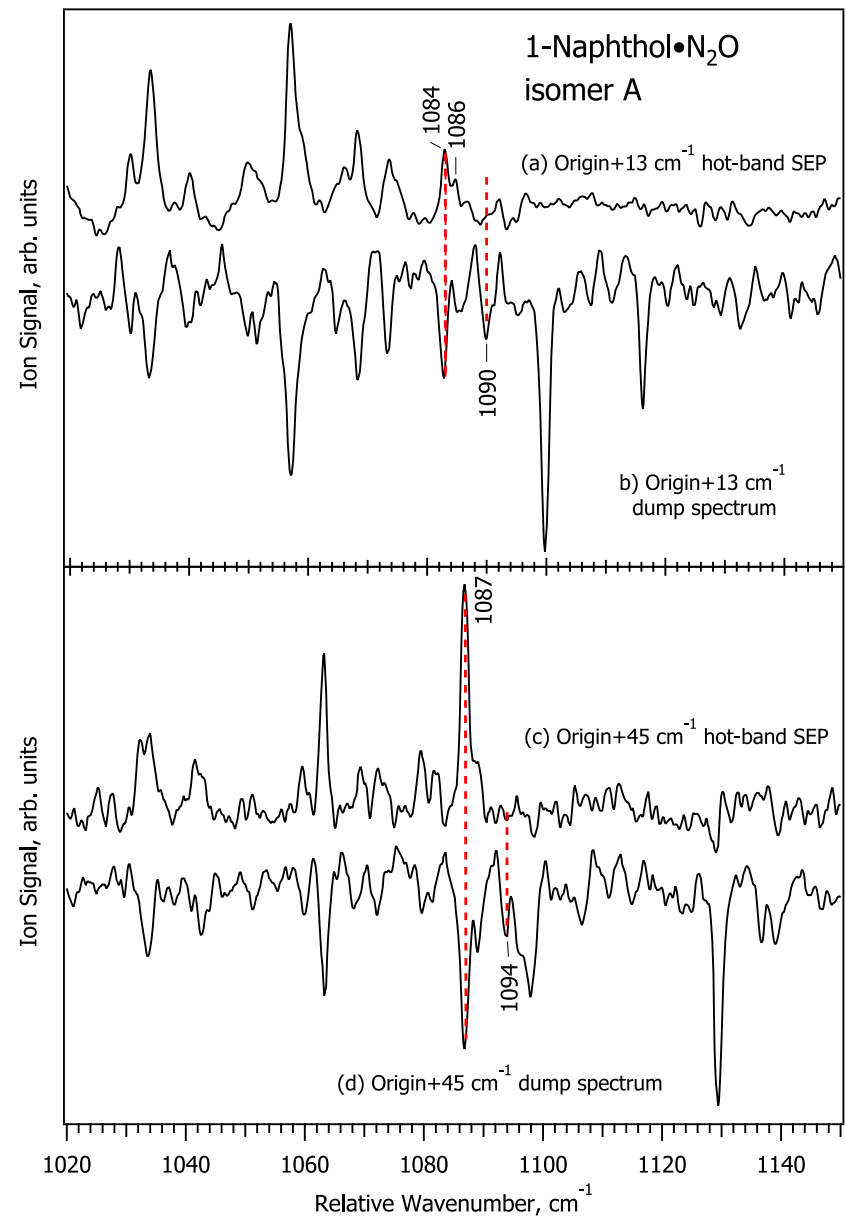

FIG. 5. Hot-band $\left(0_{0}^{0}-80 \mathrm{~cm}^{-1}\right)$ probed SEP-R2PI spectra of isomer $A$ of the $1 \mathrm{NpOH} \cdot \mathrm{N}_{2} \mathrm{O}$ complex, (a) pumped at the $0_{0}^{0}+13 \mathrm{~cm}^{-1}$ band, see Fig. $1(\mathrm{e})$, and (c) pumped at the $0_{0}^{0}+45 \mathrm{~cm}^{-1}$ band. Trace (b) is the $0_{0}^{0}+13 \mathrm{~cm}^{-1}$ dump spectrum, and (d) is the $0_{0}^{0}+45 \mathrm{~cm}^{-1}$ dump spectrum. The horizontal axis is the difference between the respective pump and the dump laser wavenumbers. In (c) and (d), the dissociation energy $D_{0}\left(S_{0}\right)$ is bracketed by the vertical red dashed lines at 1087 (or possibly 1089) $\mathrm{cm}^{-1}$ and $1094 \mathrm{~cm}^{-1}$. In (a) and (b), the bracket is defined by the peaks at $1085 \mathrm{~cm}^{-1}$ and $1090 \mathrm{~cm}^{-1}$. Using both sets of spectra, the final $D_{0}$ bracket for this complex is $1087-1090 \mathrm{~cm}^{-1}$.
Figure 5(c) shows the hot-band-detected SEP-R2PI spectrum when pumping the $0_{0}^{0}+45 \mathrm{~cm}^{-1}$ band. The ion signal was measured at a hot-band feature $80 \mathrm{~cm}^{-1}$ below the $0_{0}^{0}$ band, see Fig. S9 (supplementary material). The hot-band SEP spectrum in Fig. 5(c) closely mirrors the corresponding dump spectrum shown in Fig. 5(d) up to the band at $1087 \mathrm{~cm}^{-1}$. The next higher band in the dump spectrum which is not observed in trace 5 (c) is at $1094 \mathrm{~cm}^{-1}$. The hot-band-detected SEP-R2PI spectrum in Fig. 5(a) pumped at $0_{0}^{0}+13 \mathrm{~cm}^{-1}$ and the corresponding dump spectrum in Fig. 5(b) yield limits for $D_{0}\left(S_{0}\right)$ which are 1084 and $1090 \mathrm{~cm}^{-1}$. Taking the highest low limit and the lowest upper limit of the two experiments, the $D_{0}\left(S_{0}\right)$ is bracketed between 1087 and $1090 \mathrm{~cm}^{-1}$ giving $D_{0}\left(S_{0}\right)=1088.5 \pm 1.5 \mathrm{~cm}^{-1}$.

\section{1-Naphthol.ethyne}

Figure 6(b) shows the hot-band-detected SEP-R2PI spectrum of the ethyne complex following excitation at the $0_{0}^{0}$ band. The hot complex was detected at a hot-band feature $43 \mathrm{~cm}^{-1}$ below the $0_{0}^{0}$ band, see also Fig. S10 (supplementary material). The highestenergy vibronic band that is clearly above the noise in Fig. 6(b) is at $1191 \mathrm{~cm}^{-1}$. Comparing trace $6(\mathrm{~b})$ with the fluorescence spectrum after $0_{0}^{0}$ excitation in Fig. 6(c), one sees that the intense band at $1240 \mathrm{~cm}^{-1}$ in Fig. 6(c) is missing in Fig. 6(b), giving $D_{0}$ limits between 1191 and $1240 \mathrm{~cm}^{-1}$. Note that the weak fluorescence band at $1204 \mathrm{~cm}^{-1}$ seems to appear in Fig. 6(b), but the $\mathrm{S} / \mathrm{N}$ ratio is not large enough to warrant using this as a lower limit. To narrow the limits, we also excited the vibronic band at $0_{0}^{0}+41 \mathrm{~cm}^{-1}$, see Fig. 1(f). The respective hot-band SEP and dump spectra are shown in Figs. 6(a) and 6(d). Note the new dump band at $1206 \mathrm{~cm}^{-1}$, which lowers the upper $D_{0}$ limit. Thus, we obtain $D_{0}\left(S_{0}\right)=1198.5$ $\pm 7.5 \mathrm{~cm}^{-1}$

\section{1-Naphthol.OCS}

Figure 7(a) shows the hot-band detected SEP-R2PI spectrum of $1 \mathrm{NpOH} \cdot \mathrm{OCS}$ following laser excitation at the most intense band in the R2PI spectrum, $50 \mathrm{~cm}^{-1}$ above the $0_{0}^{0}$ band of the complex. Excitation at the strongest feature was necessary because the "hot" R2PI spectrum shows very weak hot-bands, as seen in Fig. S11 (supplementary material). Hot-band detected SEP-R2PI was measured $95 \mathrm{~cm}^{-1}$ below the $0_{0}^{0}$ band, and extensive signal averaging was necessary to obtain the spectrum in Fig. 7(a). Figures 7(b) and 7 (c) show emission spectra that were obtained by integrating the fluorescence in time windows of $40-80 \mathrm{~ns}$ after excitation [slow fluorescence, Fig. 7(b)] and 0-40 ns [fast fluorescence, Fig. 7(c)], see also the lifetimes in Table T12 (supplementary material).

Among the $1 \mathrm{NpOH} \cdot \mathrm{S}$ spectra measured so far, those in Fig. 7 are unique because (1) the hot-band detected SEP-R2PI spectrum simultaneously exhibits narrow vibronic bands and intense broader bands, (2) the fluorescence spectra exhibit only narrow bands when measured at late times, Fig. 7(b), but (3) both broad and narrow features when measured at short times.

The sharp and broad bands also show remarkable differences in the SEP-R2PI spectrum 7(a). While both are observed up to about $1140 \mathrm{~cm}^{-1}$, the intense and narrow emission bands in the $1366-1420 \mathrm{~cm}^{-1}$ region are not observed in SEP, nor are there higher-energy narrow bands. However, the broad bands continue up to $1600 \mathrm{~cm}^{-1}$ with intense peaks at 1498 and $1559 \mathrm{~cm}^{-1}$. The first 


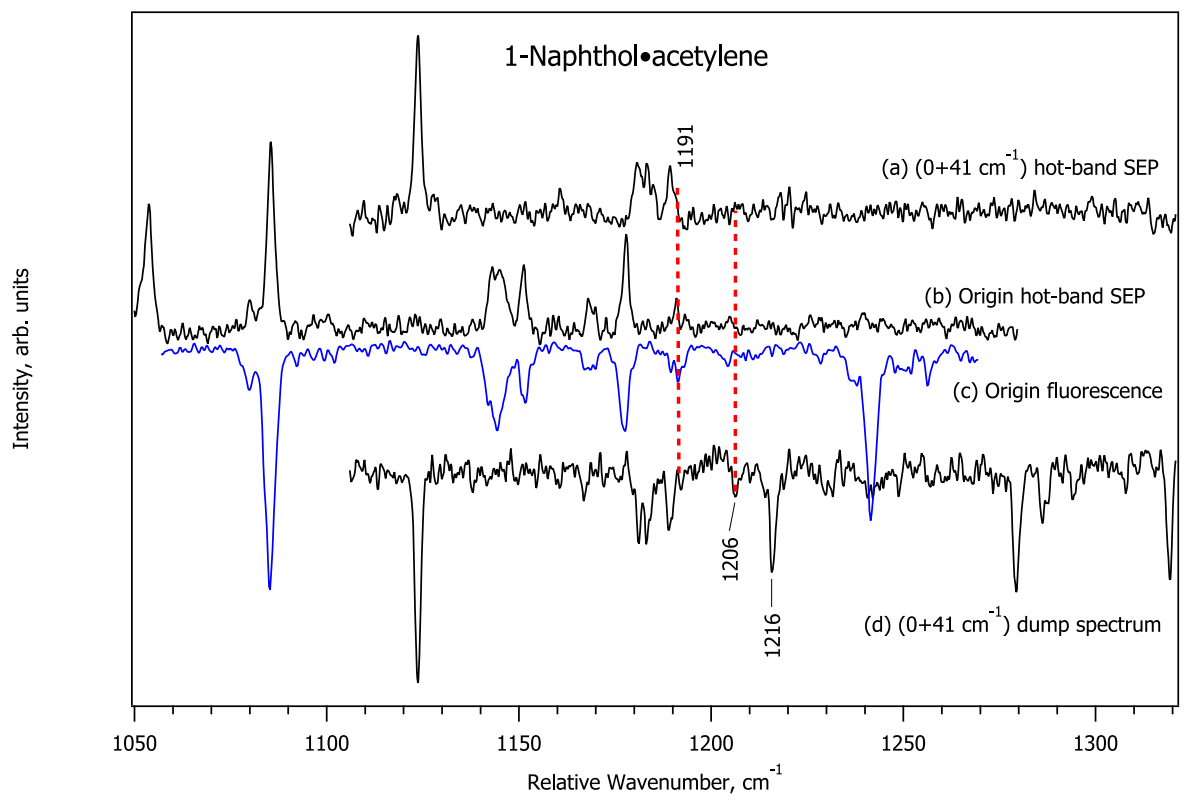

FIG. 6. Hot band $\left(0_{0}^{0}-43 \mathrm{~cm}^{-1}\right)$ probed SEP-R2PI spectrum of $1 \mathrm{NpOH}$.ethyne (a) pumped at the $0_{0}^{0}$ band and (b) at the $0_{0}^{0}+41 \mathrm{~cm}^{-1}$ band, see Fig. 1(f). (c) Inverted fluorescence spectrum of $1 \mathrm{NpOH}$.ethyne pumped at the $0_{0}^{0}$ band and (d) dump spectrum when pumping at the $0_{0}^{0}+41 \mathrm{~cm}^{-1}$ band. The horizontal axis is the difference between the pump and the dump laser wavenumbers. The $D_{0}\left(S_{0}\right)$ is bracketed by the highestenergy vibronic bands in spectra (a) and (b) at $1191 \mathrm{~cm}^{-1}$ and the next higher vibronic band, observed at $1206 \mathrm{~cm}^{-1}$ in spectrum (d), indicated by red dashed lines.

broad emission structure not seen in SEP is at $1848 \mathrm{~cm}^{-1}$. Judging by the sharp bands in Fig. 7(a), the $D_{0}\left(S_{0}\right)$ is bracketed by the bands at 1139 and $1366 \mathrm{~cm}^{-1}$, yielding $D_{0}\left(S_{0}\right)=1253 \pm 113 \mathrm{~cm}^{-1}$. Judging by the broad features, the bracket would be much higher, between 1559 and $1848 \mathrm{~cm}^{-1}, D_{0}\left(S_{0}\right)=1703 \pm 145 \mathrm{~cm}^{-1}$. We have based all previous $D_{0}$ brackets on narrow vibronic bands; furthermore, the sharp-band bracket is more consistent with the calculations reported below. We therefore propose that $D_{0}\left(S_{0}\right)=1253 \pm 113 \mathrm{~cm}^{-1}$ is the relevant value for the $1 \mathrm{NpOH} \cdot \mathrm{OCS}$ complex.
The broad features in Figs. $7(\mathrm{a})$ and 7 (c) imply that stimulated and spontaneous emission occurs from different vibrational levels. Since the pump is at $50 \mathrm{~cm}^{-1}$ above the $0_{0}^{0}$ band, see Fig. $1(\mathrm{~g})$, both fundamental and combination levels of low-wavenumber intermolecular vibrations are excited. As noted in Sec. III A, one of these is an internal-rotation mode of the OCS complex. The large band intensity implies a change of the OCS orientation in the $S_{1}$ state relative to the $S_{0}$ state minimum, this may be even a $S_{1}$ state rotational isomer, similar to the case of $p$-difluorobenzene $\mathrm{N}_{2}{ }^{43}$

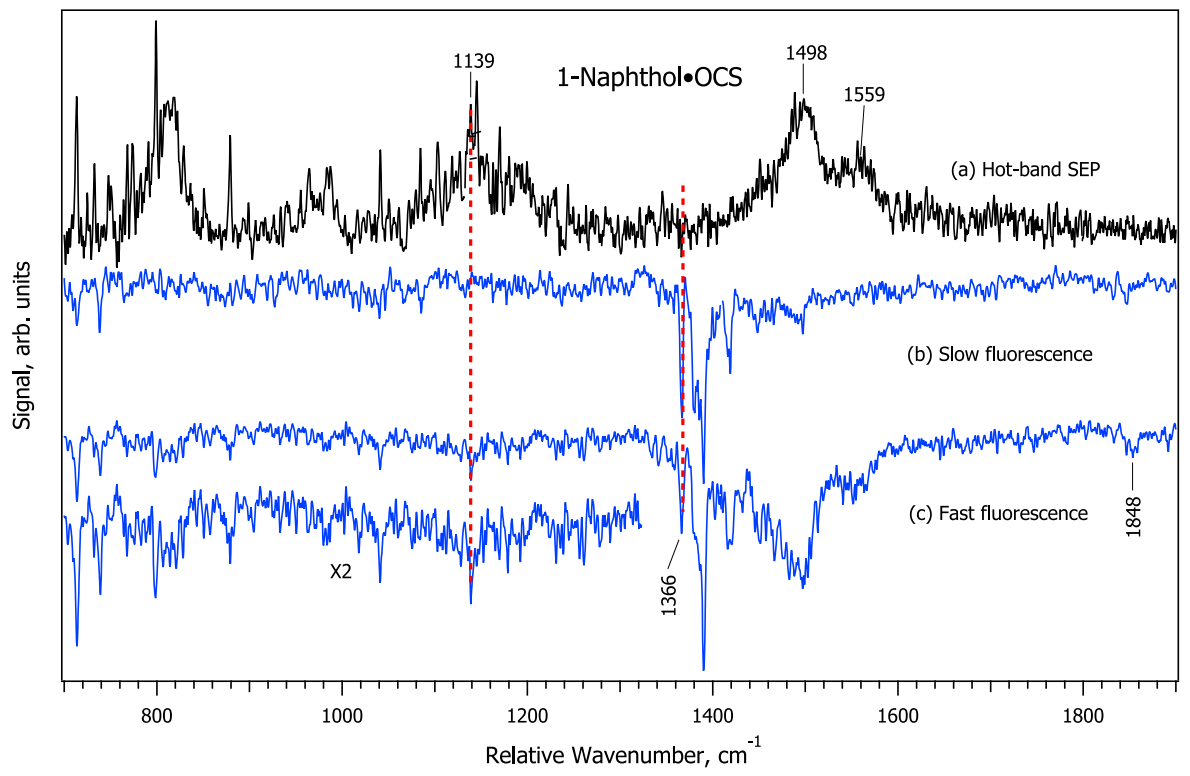

FIG. 7. (a) Hot band $\left(0_{0}^{0}-95 \mathrm{~cm}^{-1}\right)$ probed SEP-R2PI spectrum of $1 \mathrm{NpOH} \cdot \mathrm{OCS}$ and $[(\mathrm{b})$ and $(\mathrm{c})]$ corresponding inverted fluorescence spectra. Spectrum (b) was taken in a $0-40$ ns time window after excitation. For spectrum (c), the window was 40-80 ns. The probable $D_{0}\left(S_{0}\right)$ is bracketed by the vertical red dashed lines at $1139 \mathrm{~cm}^{-1}$ in spectrum (a) and $1366 \mathrm{~cm}^{-1}$ in spectrum (b). The horizontal axis is the difference between the pump and dump laser wavenumbers. See the text for further discussion. 
Since the broad features appear in the fast fluorescence and are visible in SEP (time scale a few nanoseconds), we propose that they arise from vibrationally unrelaxed levels. From this pumped superposition of levels, $S_{1}$ state IVR immediately and progressively leads to a different superposition of intermolecular levels, which are manifested in the narrow-band SEP/emission bands. Hence, at longer times (40-80 ns), spontaneous emission from the IVR-relaxed distribution is dominated by the narrow-band emission. Certain combinations of intermolecular vibrations that are formed by SEP in the ground electronic state may represent motions that couple poorly to dissociative coordinates, as in the butyne complex discussed below. This could explain why broad features in the hot SEP spectrum are observed at higher wavenumber than the likely $D_{0}\left(S_{0}\right)$.

\section{1-Naphthol-2-butyne}

Figure 8 shows the hot-band SEP spectrum of $1 \mathrm{NpOH} \cdot 2$ butyne, recorded $31 \mathrm{~cm}^{-1}$ to the red of the $0_{0}^{0}$ band, see also Fig. $S 12$ (supplementary material). Also shown in Fig. 8(a) is the $S_{1} \rightarrow S_{0}$ corresponding dispersed fluorescence spectrum. In this figure, the fluorescence spectrum was not inverted as in the preceding figures, so as to facilitate the detailed comparison of band shapes with the SEP spectrum.

The highest-wavenumber narrow band in the hot-band SEP trace that is mirrored in the fluorescence spectrum is at $2271 \mathrm{~cm}^{-1}$, which sets the lower limit to $D_{0}\left(S_{0}\right)$. Between 2271 and $2777 \mathrm{~cm}^{-1}$, both the hot-band SEP and the fluorescence spectra exhibit bands between $\sim 2440 \mathrm{~cm}^{-1}$ and $\sim 2480 \mathrm{~cm}^{-1}$. However, the bands in the hot-band SEP trace are distinctly broader and weaker than their fluorescence counterparts. As discussed below, we propose that they arise from metastable vibrational levels that undergo VP with a longer lifetime than the $3 \mu$ s delays utilized in this experiment. The upper $D_{0}$ limit would then be $2440 \mathrm{~cm}^{-1}$, but we propose as more conservative limit the lowest-energy band in the fluorescence spectrum 8 (a) that is completely absent in the hot-band SEP spectrum $8(\mathrm{~b})$, which is at $2671 \mathrm{~cm}^{-1}$. Combining this with the lower limit at $2271 \mathrm{~cm}^{-1}$, we obtain $D_{0}\left(S_{0}\right)=2471 \pm 200 \mathrm{~cm}^{-1}$.

Strong evidence for metastable levels undergoing slow VP is found near $2800 \mathrm{~cm}^{-1}$. At first glance, it might appear that the strong $2777 \mathrm{~cm}^{-1}$ fluorescence band is weakly observed in the SEP spectrum, but this is not the case. As the vertical dashed line shows, this peak is absent in the SEP spectrum, it is actually a weak shoulder at $2790 \mathrm{~cm}^{-1}$ that appears in SEP. That a strong fluorescence peak is not observed in SEP means that the corresponding dumped level is above $D_{0}$. If another peak at higher relative wavenumber is observed in SEP, the dumped level is by definition even further above $D_{0}$ and must therefore be metastable on the experimental time scale.

\section{Long-lived metastable vibrational levels: 1-Naphthol-2-butyne}

The SEP-R2PI method relies on the occurrence of efficient IVR from the dumped $S_{0}$ vibrational level of the complex into the intermolecular vibrations that eventually lead to VP of the complex if the $S_{0}$ state energy $E_{\text {exc }}$ is larger than $D_{0}$. For VP to occur, the total available internal energy $E_{\text {exc }}$ must momentarily pool in one of the "dissociative" intermolecular coordinates; i.e., in one of the three translational-type intermolecular vibrations, each of which leads to dissociation in the limit of large amplitude. The hindered rotationaltype intermolecular vibrations can also lead to dissociation, either directly or via coupling to the translational intermolecular vibrations.

The 2-butyne complex is special in that it exhibits three rotational-type vibrations with very low wavenumber all of which couple poorly to the translational intermolecular vibrations and that exhibit a very high density of states. Bunker et al. ${ }^{44}$ determined the torsional barrier in free 2-butyne to be $5.20 \mathrm{~cm}^{-1}$, so the

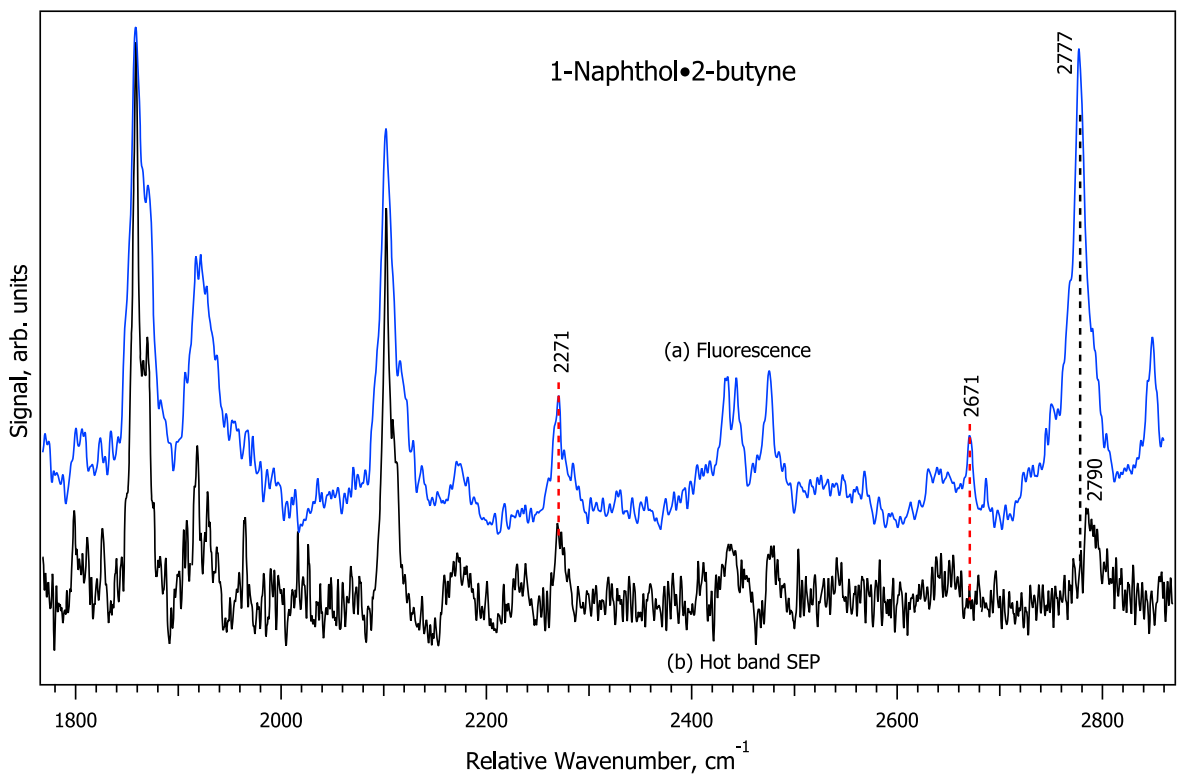

FIG. 8. (a) Origin-pumped fluorescence spectrum of $1 \mathrm{NpOH} \cdot 2$-butyne and (b) the corresponding hot band $\left(0_{0}^{0}-31 \mathrm{~cm}^{-1}\right)$ probed SEP-R2PI spectrum. The $D_{0}\left(S_{0}\right)$ is bracketed by the vertical red dashed lines at $2271 \mathrm{~cm}^{-1}$ and $2671 \mathrm{~cm}^{-1}$. The horizontal axis is the difference between the pump $\left(0_{0}^{0}\right.$ band, $\left.31340 \mathrm{~cm}^{-1}\right)$ and the dump laser wavenumbers. 
internal-rotation of the methyl groups is nearly free. We assume that this motion remains unhindered in the $1 \mathrm{NpOH}$ complex; with a level structure of a one-dimensional rotor, $E_{\text {int-rot, } 1 D}=A_{0} \cdot l^{2}$, with internal-rotation quantum number $l=0, \pm 1, \pm 2, \ldots$. Given the $D_{0}=2471 \pm 200 \mathrm{~cm}^{-1}$, IVR can populate these levels up to $l \sim \pm 32$. Furthermore, the rotation of the 2-butyne moiety around its long axis in the Edge complex (see calculated geometries below) is close to free. If we also approximate the level structure of this intermolecular vibration as an unhindered ID rotor, IVR can populate levels of this external-rotation mode up to $l \sim= \pm 30$. Finally, the rotation of the 2-butyne moiety around the $\mathrm{OH}$ hydrogen bond axis leads to a third rotation-type intermolecular mode with a $1 \mathrm{D}$ rotor energy level structure.

The combination of these low energy rotational-type motions yields a high density of nondissociating intermolecular levels at and above the dissociation limit. It seems plausible that energy stored in these levels does not flow efficiently to dissociative coordinates, which causes VP to slow to a time scale that allows a measurable fraction of the dumped population to be detected even far above the dissociation threshold.

Unfortunately, the calculation of level energies at high $E_{\text {exc }}$ is extremely difficult, so predicting the extent of VP metastability is far from straightforward, but there does seem to be a strong correlation with the presence of methyl groups in the adsorbate molecules. Out of about 35 complexes of carbazole and $1 \mathrm{NpOH}$ that have been investigated so far using the SEP-R2PI method, ${ }^{13,19,29-32,35}$ the complexes with methane and ethane and with methylated molecules such as 2,5-dimethylfuran ${ }^{35}$ and 2-butyne (this work) did not exhibit clear breaking-off points in their hot-band SEP spectra. The common characteristics of these complexes are the unhindered (or weakly hindered) rotational-type motions involving methyl groups, which give rise to a high level density. In the small alkanes, metastable vibronic bands were observed about $150-200 \mathrm{~cm}^{-1}$ above the dissociation limit. In dimethylfuran, the range was $100-300 \mathrm{~cm}^{-1}$ but was less clear due to low signal levels. As discussed above for 2-butyne, metastable vibrational bands in the hot-band SEP spectra are observed even up to about $400 \mathrm{~cm}^{-1}$ above $D_{0}$. These differences may reflect the multiple factors contributing to high state density at internal energies near the dissociation limit. In 2-butyne, these are particularly numerous, including nuclear spin states, two methyl rotors and nearly free axial rotation.

\section{Calculated structures}

Figure 9 shows the B3LYP-D3/def2-QZVPP optimized lowestenergy structures of $1 \mathrm{NpOH}$ complexed with (a) $\mathrm{CO}$ (isomer 1), (b) $\mathrm{CO}_{2}$, (c) $\mathrm{N}_{2} \mathrm{O}$ (isomer 1), (d) ethyne, (e) OCS (isomer 1), and (f) 2-butyne. The B97-D3/def2-QZVPP structures are visually indistinguishable from the B3LYP/def2-TZVPP ones. The calculated structures of the $\mathrm{N}_{2}$ complex have been reported previously. ${ }^{29}$ Two isomers were found, which were proposed to correspond to the two calculated isomers in which the $\mathrm{N}_{2}$ moiety is adsorbed over either of the aromatic rings of naphthalene. (Note that in the present work experimentally observed isomers are denoted in capital A, B, C,..., calculated isomers as $1,2,3, \ldots$; in Ref. 29, the opposite convention was used.)

The DFT-D methods predict two Face minima for the $1 \mathrm{NpOH} \cdot \mathrm{CO}$ complex, with the $\mathrm{CO}$ adsorbed on the $\mathrm{OH}$-substituted

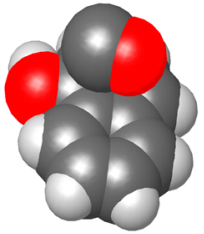

(a) 1-Naphthol $\cdot \mathrm{CO}$

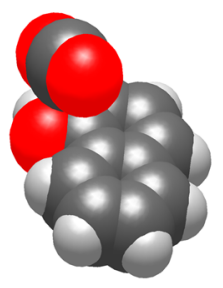

(b) 1-Naphthol $\cdot \mathrm{CO}_{2}$

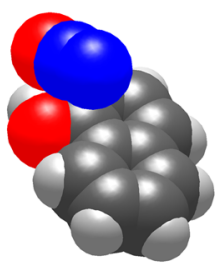

(c) 1-Naphthol $\cdot \mathrm{N}_{2} \mathrm{O}$

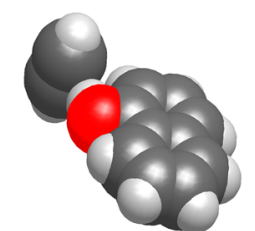

(d) 1-Naphthol $\cdot \mathrm{C}_{2} \mathrm{H}_{2}$

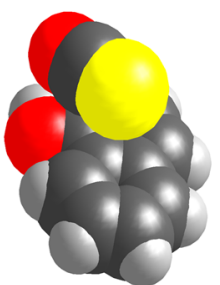

(e) 1-Naphthol • OCS

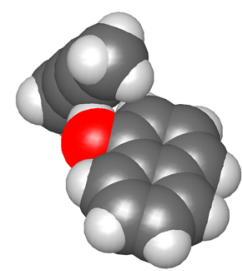

(f) 1-Naphthol $\cdot$ 2-butyne
FIG. 9. B3LYP-D3/QZVPP calculated structures of the most stable isomers of the 1-naphthol complexes with (a) CO Face, (b) $\mathrm{CO}_{2}$ Notch, (c) $\mathrm{N}_{2} \mathrm{O}$ Notch, (d) ethyne Edge, (e) OCS Notch, and (f) 2-butyne Edge. The calculated Cartesian coordinates are given in Tables T2-T11 (supplementary material).

six-ring of the naphthalene, similar to isomer 1 of $\mathrm{N}_{2} \cdot{ }^{29}$ In the lowerenergy isomer $1\left(D_{e}=9.93 \mathrm{~kJ} / \mathrm{mol}\right)$, the $\mathrm{CO}$ carbon is predicted to be closer to the naphthol $\mathrm{OH}$ group, see Fig. 9(a). In the calculated isomer 2, the CO orientation is reversed. Additional top and side views of this complex are shown in Fig. S13(a) (supplementary material), the Cartesian coordinates are given in Table T2 (supplementary material).

A single Face-type minimum was found for the $\mathrm{CO}_{2}$ complex shown in Fig. 9(b). Its geometry is different from that of all Face complexes calculated so far: the $\mathrm{CO}_{2}$ moiety does not lie flat on the naphthol ring but is shifted toward the naphthalene Edge and tilted downward into the "Notch" between the naphthalene and the $\mathrm{O}-\mathrm{H}$ group. The molecular axis is rotated $\sim 30^{\circ}$ relative to the axis of the $\mathrm{O}-\mathrm{H}$ bond. Since this structure type recurs for other linear adsorbate molecules, we denote it a Notch structure. Top and side views of this complex are shown in Fig. S13(b) (supplementary material); the Cartesian coordinates are given in Table T3 (supplementary material).

Calculations with the def2-TZVPP basis set predict five isomers of the $\mathrm{N}_{2} \mathrm{O}$ complex; here, we discuss only the two most stable ones: isomer 1 is a Notch structure very similar to that of the $\mathrm{CO}_{2}$ complex, see Fig. 9(c), Fig. S13(c), and Table T4 (supplementary material). The terminal $\mathrm{N}$ atom is close to the $\mathrm{O}$ atom of $1 \mathrm{NpOH}$, the central $\mathrm{N}$ is above the $\mathrm{O}-\mathrm{H}$ hydrogen atom, and the $\mathrm{O}$ atom of $\mathrm{N}_{2} \mathrm{O}$ makes a sideways contact with the $\mathrm{H}$ atom, giving rise to a strongly bent hydrogen bond. Its B97-D3/def2-TZVPP calculated binding energy 
is $D_{e}=-12.98 \mathrm{~kJ} / \mathrm{mol}$. In contrast, isomer 2 [Cartesian coordinates in Table T5 (supplementary material)] is a Face isomer with the $\mathrm{N}_{2} \mathrm{O}$ centered above the $\mathrm{C} 4$ atom of $1 \mathrm{NpOH}$, the terminal $\mathrm{N}$ atom over the center of the phenolic ring, and the $\mathrm{N}_{2} \mathrm{O}$ axis directed approximately along the $\mathrm{C} 4-\mathrm{C} 1-\mathrm{O}$ direction of $1 \mathrm{NpOH}$. This isomer lies $1.7 \mathrm{~kJ} / \mathrm{mol}$ higher in energy.

The calculations predict three different isomers for the OCS complex: the lowest-energy isomer 1 is a Notch structure shown in Fig. 9(e) and Fig. S14 (supplementary material); the Cartesian coordinates are given in Table T6 (supplementary material) $\left(D_{e}=-16.28\right.$ $\mathrm{kJ} / \mathrm{mol}$, B97-D3/def2-TZVPP). It is similar to the $\mathrm{CO}_{2}$ and $\mathrm{N}_{2} \mathrm{O}$ isomers shown in Figs. 9(b) and 9(c); the OCS axis being tilted downward between the $\mathrm{OH}$ and the naphthalene ring, the $\mathrm{S}$ atom lying over the center of the phenolic ring, and the $\mathrm{O}$ atom (the negative end of the OCS molecule) close to $\mathrm{O}-\mathrm{H}$ hydrogen atom, possibly forming a "sideways" hydrogen bond.

In Face isomer 2 (see Table T7 of the supplementary material), the OCS moiety lies parallel to the naphthalene ring, aligned in the $\mathrm{C} 4-\mathrm{C} 1-\mathrm{O}$ direction of the naphthol, and with the $\mathrm{S}$ atom atop the oxygen atom of the $\mathrm{OH}$ group. This isomer is the least stable of the three isomers, with a calculated binding energy $D_{e}=-13.06 \mathrm{~kJ} / \mathrm{mol}$ (B97-D3/def2-TZVPP). Isomer 3 has a Tshaped structure with the OCS axis as the stem of the T, with the $S$ atom pointing toward the naphthalene surface, see Table T8 (supplementary material). Its B97-D3/def2-TZVPP calculated binding energy is $D_{e}=-14.11 \mathrm{~kJ} / \mathrm{mol}$. The T-shaped (or "daisy") structure is a common structure motif for OCS complexes and has been experimentally observed by microwave spectroscopy of OCS with the hydrocarbons ethyne, ethene, allene, benzene, ${ }^{45}$ and cyclooctatetraene. 46,47

All the DFT-D calculations of the ethyne and 2-butyne complexes predict the most stable isomers of these complexes to be
$\mathrm{H}$-bonded Edge structures, with the $\mathrm{OH}$ group of $1 \mathrm{NpOH}$ pointing toward the center of the CC triple bond, as shown in Figs. 9(d) and 9(f); additional views are shown in Fig. S14 (supplementary material). The ethyne moiety is perpendicular to the $\mathrm{OH}$ bond, the latter being coplanar with the naphthalene moiety (Table T9 of the supplementary material). The B97-D3 calculated binding energy of this lowest-energy isomer 1 is $D_{e}=-17.60 \mathrm{~kJ} / \mathrm{mol}$. The calculations also predict two T-shaped isomers in which the $\mathrm{HCCH}$ axis is perpendicular to the naphthalene plane, with one of the ethyne $\mathrm{C}-\mathrm{H}$ groups pointing to the center of one of the naphthalene rings. These are $4 \mathrm{~kJ} / \mathrm{mol}$ less stable and therefore unlikely to be relevant here.

In contrast to ethyne, the 2-butyne moiety is predicted to be tilted relative to the $\mathrm{OH}$ group and naphthalene plane. Thereby, one of the methyl groups can approach the naphthalene moiety and maximize dispersive interactions. The $\mathrm{OH}$ group of $1 \mathrm{NpOH}$ is slightly twisted out of the naphthalene plane and points toward the central $\mathrm{C}-\mathrm{C}$ bond of the 2-butyne moiety (Table T10 of the supplementary material). There are two symmetry-equivalent (enantiomeric) minima of the intermolecular potential energy surface which can interconvert via the lowest-wavenumber intermolecular rocking mode of the complex.

\section{E. Comparisons of experimental dissociation energies}

In Fig. 10, we plot the experimental $S_{0}$ state dissociation energies of the Face and Notch complexes vs the average electronic polarizability $\bar{\alpha}$ of the admolecules. ${ }^{48}$ For comparison, we also include the experimental $D_{0}\left(S_{0}\right)$ values of the $1 \mathrm{NpOH}$ noble-gas complexes with $\mathrm{Ne}, \mathrm{Ar}, \mathrm{Kr}$, and $\mathrm{Xe}$ and with the smaller nonpolar $n$-alkanes and cycloalkanes between methane and cyclopentane; all of these also form Face complexes. ${ }^{19,29-32}$

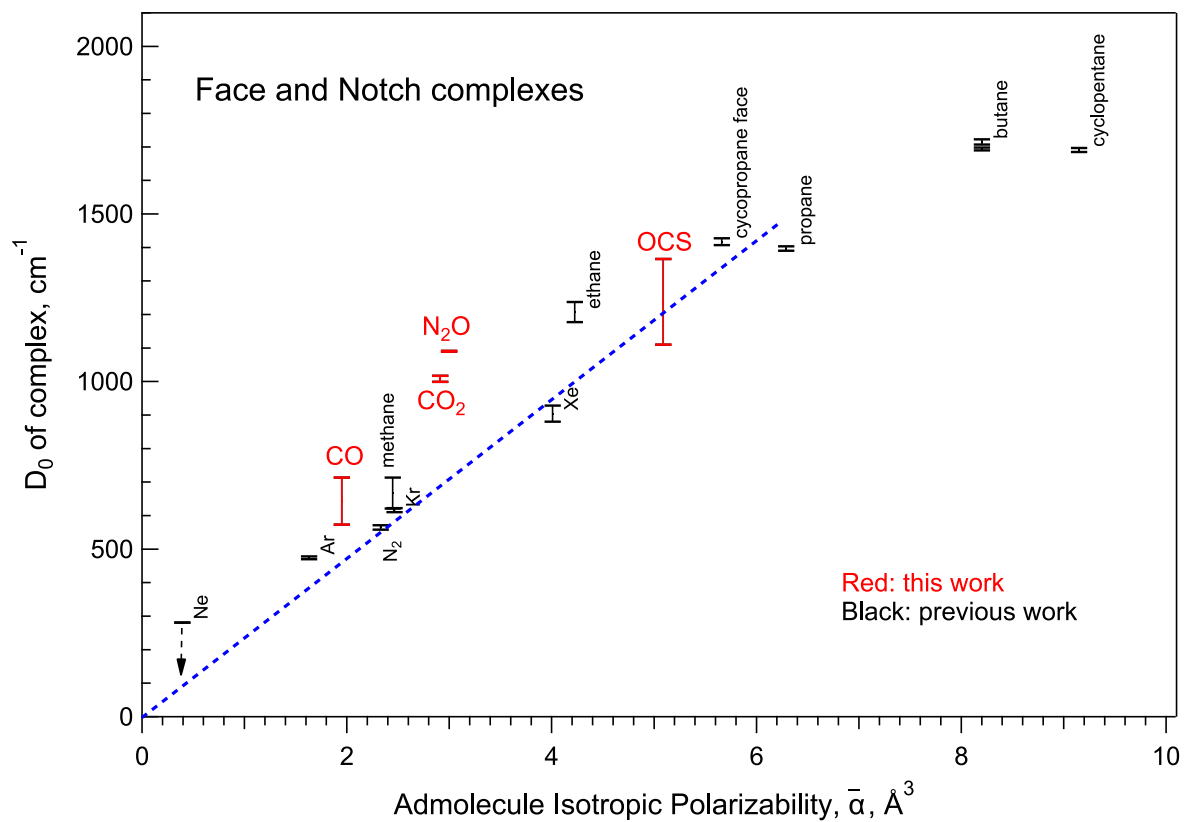

FIG. 10. Experimental ground-state dissociation energies $D_{0}\left(S_{0}\right)$ of 1-naphthol.S Face or Notch complexes vs the average electronic polarizability $\bar{\alpha}$ of the adsorbate atom or molecule. The values measured in this work for $\mathrm{S}=\mathrm{CO}$, $\mathrm{CO}_{2}, \mathrm{~N}_{2} \mathrm{O}$, and OCS are plotted in red and labeled horizontally. $D_{0}$ values from Refs. 29 and 32 are labeled vertically in black. 


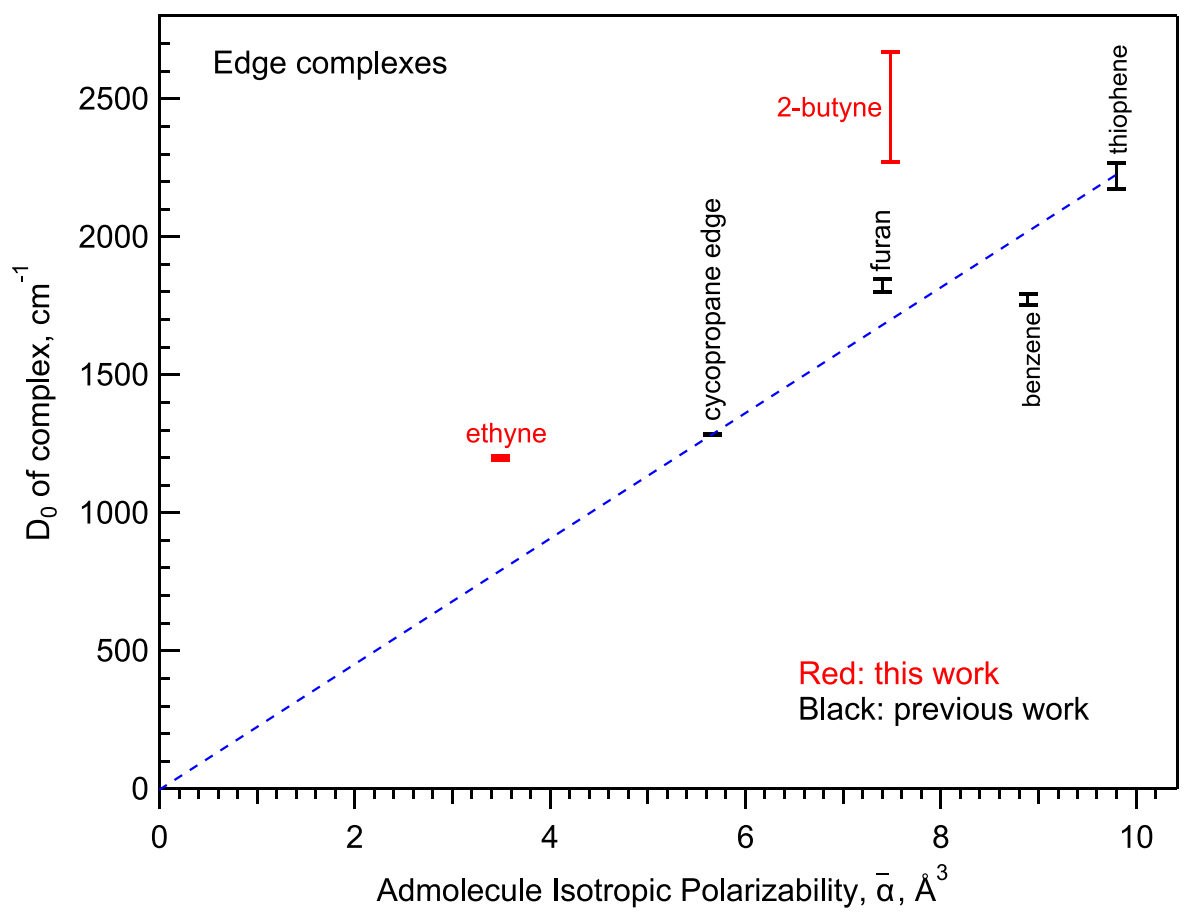

FIG. 11. Experimental SEP-R2PI dissociation energies $D_{0}\left(S_{0}\right)$ of 1-naphthol.S Edge complexes vs the average electronic polarizability $\bar{\alpha}$ of the adsorbate molecule. The values, measured in this work for $\mathrm{S}=$ ethyne and 2-butyne, plotted are in red and labeled horizontally, those from Refs. 19 and 35 are labeled vertically in black.

The dissociation energies of the linear molecules increase roughly linearly with increasing isotropic polarizability of the $S$ admolecule, similar to the correlation previously observed for the noble-gas, $n$-alkane, and cycloalkane complexes up to $n$-propane and cyclopropane. ${ }^{19,29-32}$ This correlation is indicated by a dashed blue line and is expected from the London-Eisenschitz atom-atom dispersion model. The dissociation energies of the $\mathrm{N}_{2}$ complex and the lower $D_{0}$ limits of the CO and OCS complexes are close to the $D_{0}$ values of the noble gases and (cyclo)alkanes with similar polarizability.

On the other hand, the $D_{0}$ values of the $\mathrm{CO}_{2}$ and $\mathrm{N}_{2} \mathrm{O}$ complexes and the upper $D_{0}$ limits for CO and OCS are $150-350 \mathrm{~cm}^{-1}$ larger than expected from their isotropic polarizabilities alone. We propose that these differences arise from additional stabilizing electrostatic interactions, such as between the dipole moment of $1 \mathrm{NpOH}$ and the dipole moments of $\mathrm{N}_{2} \mathrm{O}$ and $\mathrm{CO}$, and to dipole-quadrupole and quadrupole-quadrupole interactions between $1 \mathrm{NpOH}$ and the large quadrupole moment of $\mathrm{CO}_{2}, \mathrm{~N}_{2} \mathrm{O}$, and OCS. The noble-gases have no electrostatic moments, and the $n$-alkanes and cycloalkanes have zero or very small dipole moments.

For S more polarizable than propane, the Face dissociation energies are well below the correlation line for smaller molecules and increase much more slowly with polarizability. This "saturation" for Face complexes has been previously traced to the size of the admolecule. ${ }^{29,32}$ After the Face has become "covered" by the admolecule, the binding energy increases only slowly with increasing admolecule size and polarizability ${ }^{29,32}$ As Fig. 10 shows that this limit is not reached by the linear molecules discussed in this work, nor is it expected from the calculated geometries.

In contrast, the ethyne and 2-butyne admolecules form Edge complexes that are nonclassically $\mathrm{OH} \cdots \pi \mathrm{H}$-bonded to the $\mathrm{OH}$ group of $1 \mathrm{NpOH}$. In Fig. 11, we compare their $D_{0}$ values to those of the previously published $\mathrm{H}$-bonded Edge complexes of $1 \mathrm{NpOH}$ with cyclopropane, benzene, furan, and thiophene. ${ }^{35}$ Like these complexes, the experimental dissociation energies increase with the isotropic polarizability of the $\mathrm{H}$-bond acceptor. Note again that the $D_{0} \mathrm{~s}$ of ethyne and 2-butyne are significantly larger than predicted by the blue dashed correlation line that holds for the other nonclassically H-bonded complexes.

\section{DISCUSSION}

\section{A. Comparison of calculated and experimental dissociation energies}

Table III compares the experimental $D_{0}\left(S_{0}\right)$ dissociation energies to the calculated ones using the B97-D3 and B3LYP-D3 methods with the def2-QZVPP basis set. These $D_{0}$ values are derived from the calculated intermolecular binding energies $D_{e}$, and the changes of the harmonic vibrational zero-point energies $\triangle \mathrm{VZPE}$ as $D_{0}=D_{e}-\triangle \mathrm{VZPE}$, which are given in parentheses. The experimental $D_{0}$ values are also compared to the calculated ones in Fig. 12. For $\mathrm{S}=\mathrm{N}_{2}$, we compare the experimental value to the most stable calculated Face isomer 1 (see Ref. 29); for the CO, $\mathrm{N}_{2} \mathrm{O}$, and OCS complexes, we compare to the most stable Notch isomer, see Sec. III D, Fig. 9, and the supplementary material. For the $\mathrm{CO}_{2}$ complex, the DFT-D calculations predict a single Notch isomer. For ethyne and 2-butyne, we compare to the Edge isomers, which are more stable than the T-shaped isomers.

The B3LYP-D3/def2-QZVPP calculated $D_{0}$ are generally in very good agreement with the experimental values. The mean absolute deviation (MAD) between the calculated and experimental 
TABLE III. Experimental and calculated $S_{0}$ state dissociation energies $D_{0}$, binding energies $D_{e}$, and vibrational zero-point energy differences $\triangle \mathrm{VZPE}$ (in $\mathrm{kJ} / \mathrm{mol}$ ) of the 1-naphthol complexes with $\mathrm{N}_{2}, \mathrm{CO}, \mathrm{CO}_{2}, \mathrm{~N}_{2} \mathrm{O}, \mathrm{OCS}$, ethyne, and 2-butyne. The calculations were at the B97-D3/QZVPP and B3LYP-D3/QZVPP levels.

\begin{tabular}{lcccc}
\hline \hline Complex & $\begin{array}{c}\text { Experimental } \\
D_{0}\end{array}$ & $\begin{array}{c}\text { B97-D3 } \\
D_{0}\left(D_{e}-\Delta \text { VZPE }\right)\end{array}$ & $\begin{array}{c}\text { B3LYP-D3 } \\
D_{0}\left(D_{e}-\Delta \text { VZPE }\right)\end{array}$ & $\begin{array}{c}\text { D3 intermol. } \\
\text { energy }\end{array}$ \\
\hline $\mathrm{N}_{2}$ Face (1) & $6.6 \pm 0.08$ & $7.62(9.39-1.77)$ & $8.156(9.88-1.72)$ & 13.23 \\
CO Face (A) & $7.68 \pm 0.84$ & $8.073(10.00-1.92)$ & $8.092(9.93-1.84)$ & 13.00 \\
$\mathrm{CO}_{2}$ & $12.07 \pm 0.10$ & $10.54(12.74-2.19)$ & $12.36(14.67-2.31)$ & 12.74 \\
$\mathrm{~N}_{2} \mathrm{O}$ Face (A) & $13.05 \pm 0.02$ & $9.93(12.29-2.36)$ & $13.12(15.58-2.45)$ & 13.36 \\
Ethyne Edge & $14.34 \pm 0.08$ & $15.16(17.82-2.66)$ & $14.95(17.60-2.65)$ & 8.80 \\
OCS Face (A) & $14.98 \pm 1.35$ & $14.04(15.61-1.57)$ & $15.02(16.82-1.80)$ & 20.54 \\
2-butyne Edge & $29.56 \pm 1.7$ & $27.02(30.67-3.65)$ & $26.76(30.47-3.71)$ & 17.51 \\
\hline MAD $^{\mathrm{a}}$ & & 1.48 & 0.83 & \\
\hline \hline
\end{tabular}

${ }^{\mathrm{a}}$ Mean absolute deviation between the 7 calculated and experimental values.

values is $0.83 \mathrm{~kJ} / \mathrm{mol}$. The CO and OCS values lie within the experimental bracketing intervals. The others are outside the brackets, but not by much. The deviations from experiments are largest for the $\mathrm{N}_{2}$ and ethyne complexes, predictions are 1.5 and $0.6 \mathrm{~kJ} / \mathrm{mol}$ larger than the experimental upper limit.

The calculated values for 2-butyne are slightly below the lower limit of the bracket. The wide bracket in Fig. 12 gives a visual impression that the true value lies significantly higher, but it should be remembered that the upper limit was taken to be rather high due to uncertainty about the metastability of dumped levels. We note again that the true $D_{0}$ value can be anywhere in the bracketed range with equal probability.
The B97-D3/def2-QZVPP calculated $D_{0}$ values in Table III are similar to the B3LYP-D3 results with the exceptions of $\mathrm{CO}_{2}$ and $\mathrm{N}_{2} \mathrm{O}$. Correspondingly, the MAD is larger $(1.48 \mathrm{~kJ} / \mathrm{mol})$. The $\omega \mathrm{B} 97 \mathrm{X}-\mathrm{D} / 6311+\mathrm{G}(\mathrm{d}, \mathrm{p})$ calculated dissociation energies are listed in Table T1 (supplementary material). They are all smaller than the experimental ones, leading to the largest MAD $(1.68 \mathrm{~kJ} / \mathrm{mol})$.

In Table III, we also collected the intermolecular D3 dispersion energy contributions, which were calculated at the B3LYPD3/def2-QZVPP optimized geometries. The interesting result is that for all the Face and Notch complexes studied here, the D3 dispersion energy is larger than the $D_{0}$. In other words, without the D3 dispersion contribution, these complexes would not be bound (at least

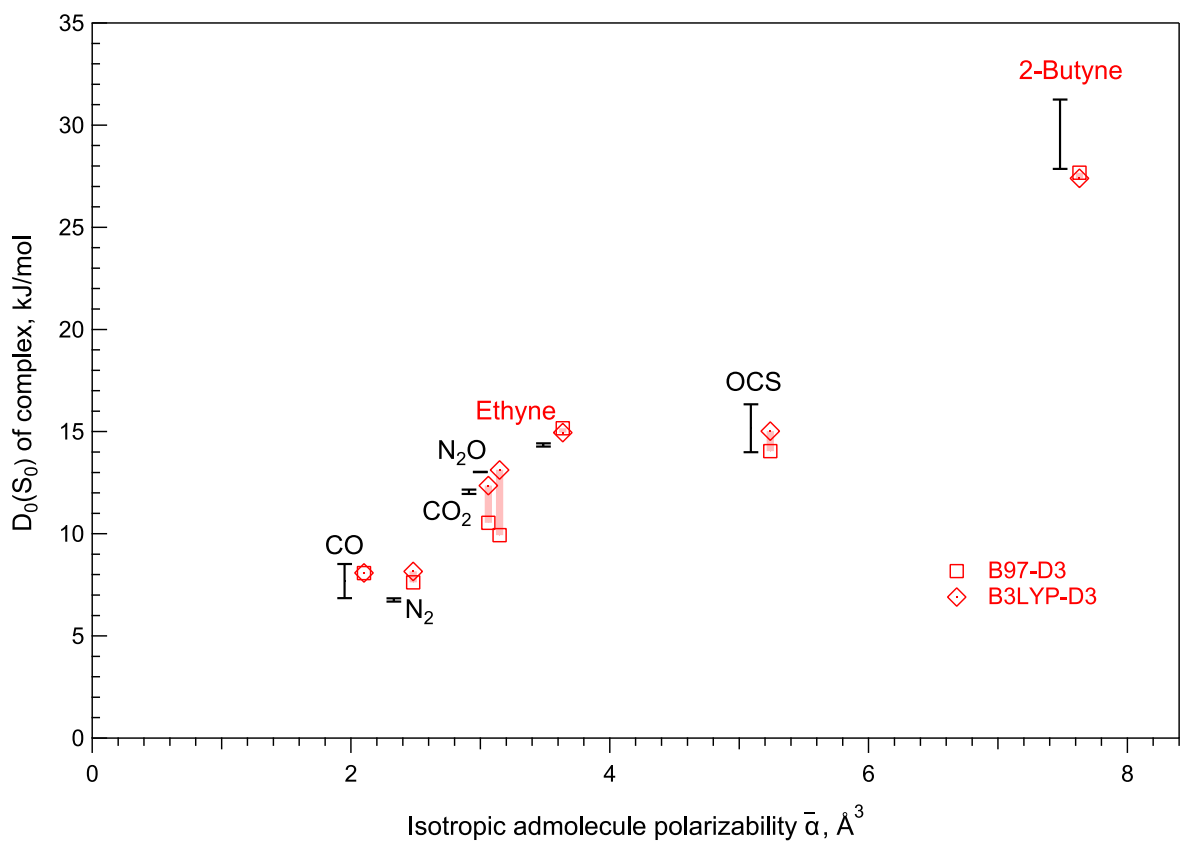

FIG. 12. Comparison of experimental and calculated SEP-R2PI groundstate dissociation energies $D_{0}\left(S_{0}\right)$ of the 1-naphthol.S complexes with $\mathrm{S}=\mathrm{CO}, \mathrm{N}_{2}$, $\mathrm{CO}_{2}, \mathrm{~N}_{2} \mathrm{O}$, ethyne, OCS, and 2-butyne, plotted vs the isotropic electronic polarizability $\bar{\alpha}$ of the adsorbate molecule. Face or Notch complexes are labeled in black, and Edge complexes are in red. See also Table II. 
not in their Face or Notch geometries). For the ethyne and 2-butyne Edge complexes on the other hand, the D3 energy contribution is smaller than the B3LYP-D3/def2-QZVPP dissociation energy, implying that these complexes would also be $\mathrm{H}$-bonded without the dispersion contribution. However, the dispersion contribution remains large in these cases, being about $60 \%$ of the total dissociation energies.

\section{B. Vibrational zero-point energies}

When comparing calculated $D_{0}$ values to experiments, the $\triangle$ VZPE values also need to be considered, since good $D_{0}$ values might arise from the error compensation of erroneous well depths $D_{e}$ and $\triangle$ VZPE values. Columns 3 and 4 of Table III include both $D_{e}$ and vibrational zero-point energy changes $\triangle \mathrm{VZPE}$ in parentheses. The B97-D3/def2-QZVPP and B3LYP-D3/def2-QZVPP binding energies in Table III are similar; the B3LYP-D3 values being about $5 \%$ or $0.5-1.9 \mathrm{~kJ} / \mathrm{mol}$ larger than the B97-D3 values. However, the $\triangle \mathrm{VZPE}$ values calculated with the two functionals are mutually much closer, being within $0.25 \mathrm{~kJ} / \mathrm{mol}$ of each other. Thus, the differences in the calculated $D_{0}$ values derive mostly from differences of the $D_{e}$ s.

Table III shows that $\triangle \mathrm{VZPE}$ is $15 \%-20 \%$ of $D_{e}$ for the $\mathrm{N}_{2}$, $\mathrm{CO}, \mathrm{CO}_{2}, \mathrm{~N}_{2} \mathrm{O}$, and ethyne complexes, decreasing to $12 \%$ of $D_{e}$ for the 2-butyne complex and to $10 \%$ of $D_{e}$ for the OCS complex. Thus, the $\triangle \mathrm{VZPE}$ corrections substantially influence the $D_{0}$ values. For the $1 \mathrm{NpOH} \cdot \mathrm{S}$ noble-gas complexes $(\mathrm{S}=\mathrm{Ne}-\mathrm{Xe})$, the $\triangle \mathrm{VZPE}$ contributions were smaller between $7 \%$ and $12 \%$ of the $D_{e} \cdot{ }^{29}$ The difference arises mainly from the smaller number of intermolecular vibrations for the noble-gas complexes (three), while the linear admolecule complexes have five intermolecular vibrations (six for 2-butyne).

Table I shows that the intermolecular VZPE contributes $60 \%-90 \%$ to the total $\triangle$ VZPE. The other contribution to $\triangle \mathrm{VZPE}$ arises from the changes of the intramolecular vibrational frequencies of the two moieties upon complex formation, $\Delta_{\text {intra }}{ }^{32}$ This contribution has a net positive sign, as a consequence of the slight compression of both complex partners by the dispersive intermolecular interaction which-on average-increases the intramolecular frequencies. The individual calculated frequency changes are small, typically between -5 and $+10 \mathrm{~cm}^{-1}$.

Some of the DFT-D calculated intermolecular vibrational frequencies, and hence to some extent the $\triangle \mathrm{VZPE}$ values, can be compared to experiments. The R2PI spectra of the linear-molecule complexes in Fig. 1 exhibit fundamental excitations of the translational-type intermolecular vibrations $\tilde{v}_{X}, \tilde{v}_{Y}$, and $\tilde{v}_{Z}$, in some cases also distinct fundamentals of the rotational-type intermolecular vibrations $\tilde{v}_{r o t, 1}$ and $\tilde{v}_{r o t, 2}$ also appear. Since the excited-state $D_{0}$ values are very close to the $S_{0}$ state $D_{0}$ s, we expect that the $S_{1}$ state fundamental intermolecular vibrational wavenumbers differ little from their $S_{0}$ state counterparts (with the possible exception of the OCS complex), which were not measured. Table I compares the B3LYP-D3 calculated (harmonic) and experimental $S_{1}$ state intermolecular frequencies. Many differ by only a few $\mathrm{cm}^{-1}$, the largest differences being $18 \mathrm{~cm}^{-1}(0.1-0.2 \mathrm{~kJ} / \mathrm{mol})$. Judging from the B3LYP-D3/def2-QZVPP calculated frequencies, $60 \%-70 \%$ of the intermolecular VZPE of these complexes arises from the two rotational-type intermolecular vibrations. The R2PI spectra yields less information on these fundamentals, since the electronic excitation of the $1 \mathrm{NpOH}$ moiety couples weakly to the rotational-type intermolecular coordinates, resulting in low Franck-Condon factors for these modes.

\section{Face, Notch, or Edge?}

The spectral shift $\delta \tilde{v}$ of the $S_{0} \rightarrow S_{1}$ origin band of $1 \mathrm{NpOH}$ has so far proven to be a reliable and convenient predictor of the binding topology of the $1 \mathrm{NpOH}$ intermolecular complexes. ${ }^{19,29-32,35}$ In the dispersively bound Face complexes involving noble-gas atoms or $\mathrm{N}_{2}$, the spectral shifts ranged between $\delta \tilde{v}=-2 \mathrm{~cm}^{-1}$ for $\mathrm{S}=\mathrm{Ne}$ and $-35 \mathrm{~cm}^{-1}$ for $\mathrm{S}=\mathrm{Xe} .^{29,42}$ Similarly, the Face isomer of $1 \mathrm{NpOH} \cdot$ cyclopropane exhibits a small spectral blue shift of $\delta \tilde{v}=+2$ $\mathrm{cm}^{-1} ;{ }^{19,30}$ for $1 \mathrm{NpOH} \cdot$ cyclohexane, the shift is $\delta \tilde{v}=-1.7 \mathrm{~cm}^{-1}$.

However, if the admolecule is classically $\mathrm{H}$-bonded to the $-\mathrm{OH}$ group of $1 \mathrm{NpOH}$, as in the $\mathrm{H}_{2} \mathrm{O}, \mathrm{CH}_{3} \mathrm{OH}$, and $\mathrm{NH}_{3}$ complexes, the spectral red shifts are much larger, being $\delta \tilde{v}=-145,-158$, and $-236 \mathrm{~cm}^{-1}$, respectively, ${ }^{36,38}$ The shift of the H-bonded cyclopropane Edge isomer is $\delta \tilde{v}=-72 \mathrm{~cm}^{-1}$, much larger than that of the respective Face isomer. ${ }^{19,30}$ The spectral shifts of the nonclassically $\mathrm{H}$-bonded $1 \mathrm{NpOH}$ complexes with the (hetero)aromatics benzene, furan, thiophene, and 2,5-dimethylfuran range from $-66 \mathrm{~cm}^{-1}$ for benzene to $-93 \mathrm{~cm}^{-1}$ for the 2,5-dimethylfuran complex. ${ }^{35,36}$

If we employ the spectral shift as a structure predictor for the linear molecules measured here, we expect the complexes with ethyne, 2-butyne, $\mathrm{CO}$, and possibly OCS to be H-bonded Edge structures. Indeed, the DFT-D calculations support this conclusion for ethyne and 2-butyne. For CO and OCS, the situation is much less clear. Note that the $-71 \mathrm{~cm}^{-1}$ red shift of the CO complex is very close to that of the Edge isomer of $1 \mathrm{NpOH} \cdot$ cyclopropane $\left(-72 \mathrm{~cm}^{-1}\right)$ and is larger than that of $1 \mathrm{NpOH} \cdot$ benzene $\left(-66 \mathrm{~cm}^{-1}\right)$, which has an Edge geometry. ${ }^{49}$ Furthermore, Fig. 1 shows that the $S_{0} \rightarrow S_{1}$ vibronic spectrum of the $1 \mathrm{NpOH} \cdot \mathrm{CO}$ complex is qualitatively similar to the spectra of the ethyne and 2-butyne complexes, both of which have Edge structures. Like these two complexes, the R2PI spectrum of $1 \mathrm{NpOH} \cdot \mathrm{CO}$ shows sparse and well-resolved vibronic bands with near-zero Franck-Condon factors in the low-frequency rotational-type modes. Nevertheless, although we attempted the DFT-D minimizations of $1 \mathrm{NpOH} \cdot \mathrm{CO}$ from a large variety of Edge starting geometries, they all lead to the two Face minima described in Sec. III E. Similarly, minimizations of the $1 \mathrm{NpOH} \cdot \mathrm{OCS}$ complex starting from Edge geometries always led to Notch, Face, or T-shaped geometries, see Sec. III E. These two complexes provide the first clear discrepancies between the spectralshift structure predictor and the DFT-D predicted lowest-energy structures.

The $\mathrm{CO}_{2}$ and $\mathrm{N}_{2} \mathrm{O}$ Notch complexes exhibit larger blue shifts of the origin than any $1 \mathrm{NpOH}$ complex measured previously. Together with the large red shifts of the OCS Notch and CO Face complexes, this group of complexes appears to be exceptional. They must experience unusually large changes in the electrostatic parts of the intermolecular interaction upon $S_{0} \rightarrow S_{1}$ excitation, compared to complexes with nonpolar admolecules such as the noble gases, $n$-alkanes and cycloalkanes. Particularly for the Notch complexes, this might result from close interaction with the naphthol $\mathrm{OH}$ group. However, more detailed calculations would be necessary to understand the different electrostatic contributions. For example, the $\mathrm{CO}_{2}$ and OCS 
complexes are calculated to have very similar Notch structures, with the $\mathrm{O}-\mathrm{C}-$ end of the admolecule adjacent to the $\mathrm{H}-\mathrm{O}-$ of the naphthol. Yet, the spectral shift of the $0_{0}^{0}$ band of the $\mathrm{CO}_{2}$ complex is to the blue by $20 \mathrm{~cm}^{-1}$, while that of the OCS complex is $72 \mathrm{~cm}^{-1}$ to the red.

\section{Electrostatic moments and complex geometry}

Given the possible effects of electrostatic intermolecular interactions discussed in Sec. IV C, we looked for correlations of the electrostatic moments of the seven admolecules treated here with the geometries of the $1 \mathrm{NpOH}$ complexes.

\section{Dipole moments}

Only three of the seven admolecules ( $\mathrm{CO}, \mathrm{N}_{2} \mathrm{O}$, and OCS) have a dipole moment. Furthermore, the dipole moments of $\mathrm{N}_{2} \mathrm{O}(0.07 \mathrm{D})$ and CO $(0.10 \mathrm{D})$ are small, and that of OCS $(0.78 \mathrm{D})$ is moderate. Both $\mathrm{N}_{2} \mathrm{O}$ and OCS exhibit Notch geometries and CO has a Face geometry; on the other hand, the nonpolar $\mathrm{N}_{2}$ molecule has a Face geometry, nonpolar $\mathrm{CO}_{2}$ has a Notch geometry, and the nonpolar ethyne and 2-butyne complexes have Edge geometries. There are no obvious correlations between the admolecule dipole moment and the geometry of the complex.

\section{Quadrupole moments}

In Table IV, we list the experimental and calculated traceless quadrupole moment tensor components $\Theta_{i i}(i=y, z)$ of the seven

TABLE IV. B3LYP-D3/def2-QZVPP calculated and experimental traceless quadrupole moment tensor components $\Theta_{y y}$ and $\Theta_{z z}$ (in Debye $\left.\AA^{2}\right)^{a}$ of the molecules $\mathrm{N}_{2}, \mathrm{CO}, \mathrm{CO}_{2}, \mathrm{~N}_{2} \mathrm{O}$, OCS, ethyne, 2-butyne, benzene, furan, and thiophene.

\begin{tabular}{lcccc}
\hline \hline Admolecule & $\Theta_{y y}$ & $\Theta_{z z}$ & $\Theta_{y y}($ expt. $)$ & $\Theta_{z z}$ (expt.) \\
\hline $\mathrm{N}_{2}$ & +0.53 & -1.06 & & $-1.49 \pm 0.05^{\mathrm{b}}$ \\
$\mathrm{CO}$ & +0.69 & $-1.46^{\mathrm{c}}$ & & $-1.94 \pm 0.039^{\mathrm{d}}$ \\
$\mathrm{CO}_{2}$ & +1.50 & -3.00 & & $-4.29 \pm 0.18^{\mathrm{e}}$ \\
$\mathrm{N}_{2} \mathrm{O}$ & +1.31 & -2.63 & & $-3.65 \pm 0.25^{\mathrm{f}}$ \\
Ethyne & -2.19 & +4.37 & & $+4.71 \pm 0.14^{\mathrm{g}}$ \\
OCS & +0.40 & -0.80 & & $-0.88 \pm 0.15^{\mathrm{h}}$ \\
2-butyne & -2.13 & +4.26 & & $+5.33 \pm 0.28^{\mathrm{g}}$ \\
\hline Benzene & & & & $-9.11 \pm 0.36^{\mathrm{i}}$ \\
Furan & +5.88 & -5.46 & $+5.91 \pm 0.30$ & $-6.09 \pm 0.36^{\mathrm{j}}$ \\
Thiophene & +5.85 & -6.48 & $+6.6 \pm 1.5$ & $-8.30 \pm 2.2^{\mathrm{j}, \mathrm{k}}$ \\
\hline \hline
\end{tabular}

a1 Debye $\AA^{2}=3.33564 \times 10^{-40} \mathrm{C} \mathrm{m}^{2}$.

${ }^{\mathrm{b}}$ Reference 51.

${ }^{c}$ Reference 52, CCSD(T)/d-aug-cc-pV6Z level.

${ }^{\mathrm{d}}$ Reference 53 .

${ }^{\mathrm{e}}$ Reference 54 .

${ }^{\mathrm{f}}$ Reference 55.

${ }^{g}$ Reference 56.

${ }^{\mathrm{h}}$ Reference 57.

${ }^{\mathrm{i}}$ Reference 58.

${ }^{\mathrm{j}}$ Reference 59.

${ }^{\mathrm{k}}$ MP2 calculations from Ref. 60, experimental values from Ref. 61. admolecules, plus those of three admolecules that also form Edge complexes. Note that for linear and symmetric-top molecules, the $z$ axis of the quadrupole moment tensor is the molecular $C_{\infty}$ symmetry axis, and $\Theta_{x x}=\Theta_{y y}$ by symmetry. Furthermore, $\Theta_{y y}=-0.5 \cdot \Theta_{z z}$ because the tensor is traceless.

For the admolecules benzene, furan and thiophene, the $z$ axis is taken as the normal to the molecular plane; note that for the $C_{2 v}$ furan and thiophene molecules, $\Theta_{x x} \neq \Theta_{y y}$. A positive sign of $\Theta_{z z}$ indicates a quadrupolar field anisotropy that arises from net positive charge on the $C_{\infty}$ axis near the ends of the admolecule combined with net negative charge in the directions perpendicular to the $C_{\infty}$ axis. Thus, the large positive $\Theta_{z z}$ of ethyne might be rationalized as arising from the slightly positive $\mathrm{H}$ atoms located at the ends of the molecule together with the negative charge accumulated in the two off-axis $\pi$-orbitals. Note, however, that electrons in filled $\pi$-orbitals do not automatically give rise to positive $\Theta_{z z}$, as can be seen in $\mathrm{N}_{2}, \mathrm{CO}, \mathrm{CO}_{2}, \mathrm{~N}_{2} \mathrm{O}$, and OCS, which all have negative $\Theta_{z z}$ values, which implies net negative charge on the $C_{\infty}$ axis near the ends of the molecule combined with net positive charge accumulated in the directions perpendicular to the $C_{\infty}$ axis.

If we assume the CO complex to have the DFT-D predicted Face geometry, a consistent correlation emerges between the sign of $\Theta_{z z}$ and the geometry of the complex. All complexes in which $S$ has negative $\Theta_{z z}$ exhibit Face or Notch geometries. On the other hand, the two alkynes studied here have positive $\Theta_{z z}$ and exhibit $\mathrm{H}$ bonded (Edge) geometries. Figure 13 shows that this correlation is intuitively plausible. In the $\mathrm{N}_{2}$ and $\mathrm{CO}$ complexes, the admolecules are positioned such that the interaction of the net positive central quadrupole ring with the electron-rich $\pi$-system of the naphthalene moiety is stabilizing, see Fig. 13(a). Figure 13(b) uses the example of $\mathrm{CO}_{2}$ to illustrate the orientation of the quadrupole moment in the Notch complexes. In these cases, the interaction with the $\pi$-electrons of the naphthalene moiety and that with one end of the quadrupole moment with the dipole of the $\mathrm{OH}$ group are attractive. In Fig. 13(c), it is apparent that for ethyne the Edge geometry combined with the positive $\Theta_{z z}$ leads to an attractive interaction with the net positively charged $\mathrm{H}$ atom of the $\mathrm{OH}$ group.

We also note that this correlation can be extended to the $1 \mathrm{NpOH}$ complexes with benzene, furan and thiophene, which have H-bonded Edge geometries. ${ }^{35}$ Table IV shows that their $\Theta_{z z}$ values are large and negative, where the $z$ axis is perpendicular to the molecular plane. For these three admolecules, the quadrupole moment of the admolecule is also oriented such that the negative lobe of $\Theta_{z z}$ is directed toward the (positive) $\mathrm{H}$ atom of the $\mathrm{OH}$ bond.

While the above correlations of the DFT-D calculated minimum-energy geometries with the signs of $\Theta_{z z}$ are consistent, it is not possible to use the admolecule quadrupole moment as a predictor for the lowest-energy geometry. Thus, the positive $\Theta_{z z}$ of ethyne also leads to an attractive interaction in T-shaped geometries with the $\mathrm{C}-\mathrm{H}$ bond pointing toward the naphthalene ring. In fact such a geometry is predicted by the DFT-D calculations as one of the energetically higher-lying isomers of the $1 \mathrm{NpOH} \cdot$ ethyne complex. Analogously, the negative $\Theta_{z z}$ of $\mathrm{N}_{2}, \mathrm{CO}, \mathrm{CO}_{2}, \mathrm{~N}_{2} \mathrm{O}$, and OCS would lead to stabilizing interactions with the $-\mathrm{OH}$ hydrogen atom in near-collinear - $\mathrm{OH} \cdots \mathrm{S}$ hydrogen bonds. If the $\mathrm{S}$ atom of OCS and the $\mathrm{C}$ atom of $\mathrm{CO}$ were closer to the $\mathrm{OH}$ hydrogen, the geometry would also be favored by the dipole moments of these two 


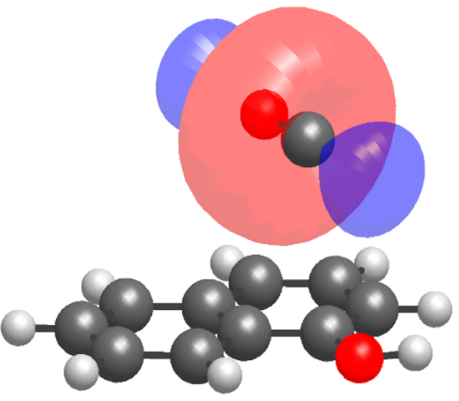

(a) Face complex

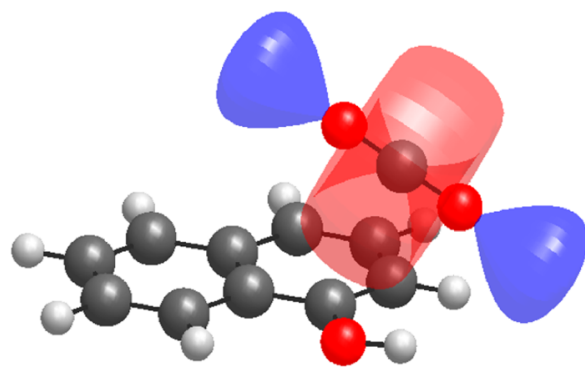

(b) Notch complex

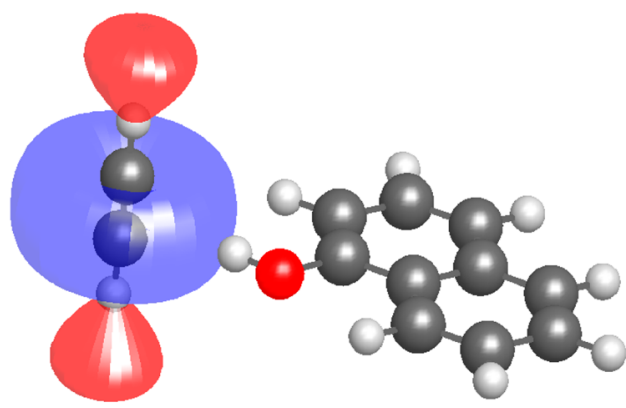

(c) Edge complex

FIG. 13. Calculated structures of (a) the 1-naphthol.CO Face, (b) the 1-naphthol. $\mathrm{CO}_{2}$ Notch, and (c) the 1-naphthol-ethyne Edge complexes, with schematic representations of the admolecule quadrupole moments. The lobes of the quadrupoles are colored according to the net excess charge as given by the sign of the quadrupole moments (red = positive excess charge and blue $=$ negative). See the text for discussion.

molecules. However, for $\mathrm{N}_{2}, \mathrm{CO}, \mathrm{CO}_{2}, \mathrm{~N}_{2} \mathrm{O}$, and OCS, the DFT-D calculations do not even predict stable minima in the $\mathrm{H}$-bonded orientation.

\section{CONCLUSIONS}

Intermolecular dissociation energies $D_{0}$ of the 1-naphthol complexes with the linear molecules $\mathrm{N}_{2},{ }^{29} \mathrm{CO}, \mathrm{CO}_{2}, \mathrm{OCS}, \mathrm{N}_{2} \mathrm{O}$, ethyne, and the closely related symmetric-top molecule 2-butyne have been experimentally determined using the stimulated-emission pumping resonant two-photon ionization (SEP-R2PI) method. The ground-state dissociation energies $D_{0}\left(S_{0}\right)$ were bracketed within less than $\pm 0.1 \mathrm{~kJ} / \mathrm{mol}$ for $\mathrm{S}=\mathrm{N}_{2}, \mathrm{CO}_{2}, \mathrm{~N}_{2} \mathrm{O}$, and ethyne complexes, within $\pm 1.2 \mathrm{~kJ} / \mathrm{mol}$ for the CO and OCS complexes, and within $\pm 1.7 \mathrm{~kJ} / \mathrm{mol}$ for the 2-butyne complex.

The spectral shifts of these linear-molecule complexes, which are equivalent to the changes of the dissociation energies upon excitation to the $S_{1}$ excited state, are quite diverse, ranging from a relative decrease of $-2 \%$ for the $\mathrm{CO}_{2}$ Notch complex to a relative increase of $+12 \%$ for the CO Face complex. Comparison of the spectral shifts of the $\mathrm{CO}, \mathrm{CO}_{2}, \mathrm{~N}_{2} \mathrm{O}$, and OCS complexes shows that the previously observed correlation between the structures and the spectral shifts $^{19,29-32,35}$ does not hold for these Notch complexes. We hypothesize that this arises from the spatial proximity of these strongly quadrupolar molecules to the $-\mathrm{OH}$ group of $1 \mathrm{NpOH}$, leading to changes of electrostatic interactions approaching $\pm 0.7 \mathrm{~kJ} / \mathrm{mol}$ upon $S_{0} \rightarrow S_{1}$ excitation. On the other hand, the correlation of DFT-D predicted Edge geometries of the ethyne and 2-butyne complexes with large red-shifts still holds, in line with the correlation found for the complexes with benzene, furan, 2,5-dimethylfuran, tetrahydrofuran, and other H-bonded complexes. ${ }^{34,35,38}$

The $D_{0}\left(S_{0}\right)$ values of the newly measured Face and Notch complexes increase monotonically with increasing average electronic polarizability $\bar{\alpha}$ of the admolecule, in qualitative agreement with the Eisenschitz-London atom-atom model for dispersive interactions. ${ }^{1,2}$ Combining the SEP-R2PI dissociation energies of the linear molecule complexes with those of the previously measured dispersively bound noble-gas atoms ${ }^{29}$ and the $n$-alkane and cycloalkane Face complexes of $1 \mathrm{NpOH}^{19,30,32}$ confirms a roughly linear correlation of dissociation energies between $D_{0}=480$ and $1400 \mathrm{~cm}^{-1}$ with average electronic polarizability $\bar{\alpha}$ between 1.6 and $6.5 \AA^{3}$. For solvent molecules with larger $\bar{\alpha}$, the dissociation energy saturates with increasing $\bar{\alpha}$, as discussed before. ${ }^{29,32}$

Structures, binding energies $D_{e}$, vibrational frequencies, and changes of vibrational zero-point energy $(\triangle \mathrm{VZPE})$ of the complexes were calculated using the three dispersion-corrected density functional methods B97-D3, B3LYP-D3, and $\omega$ B97X-D with triple-zeta basis sets, followed by calculations of the respective lowest-energy isomers using the B97-D3 and B3LYP-D3 methods and the def2QZVPP quadruple-zeta basis set. The geometries change very little between the TZVPP and QZVPP calculations. The $\mathrm{N}_{2}$ and CO complexes are predicted to be Face complexes. The $\mathrm{CO}_{2}, \mathrm{~N}_{2} \mathrm{O}$, and OCS complexes exhibit a novel geometry type in which the linear molecule is adsorbed in the "Notch" between the naphthyl and $\mathrm{OH}$ moieties of $1 \mathrm{NpOH}$. It would be important to experimentally check, e.g., by microwave spectroscopy, that this DFT-D theoretical prediction of a novel structure type is correct. In contrast, the lowestenergy isomers of the ethyne and butyne complexes are $\mathrm{H}$-bonded Edge geometries.

In earlier work, the (BSSE-uncorrected) B97-D3 method with the TZVPP basis set best reproduced the experimental $D_{0}$ values, closely followed by the B3LYP-D3 method with the same basis set. $^{19,29-32,35}$ In going to the larger QZVPP basis set, this is reversed for the complexes studied here with the B3LYP-D3/QZVPP method performing slightly better $(\mathrm{MAD}=0.83 \mathrm{~kJ} / \mathrm{mol})$. As shown in the last column of Table III, the D3 dispersion energy at the minimumenergy geometry is calculated to be large and stabilizing for the Face and Notch complexes typically $1.2-2$ times the $D_{0}$. Thus, 
without the D3 corrections to the density functionals, these complexes would not be bound in their equilibrium Face and Notch geometries.

The VZPE contribution to $D_{0}$ and the $\triangle$ VZPE correction were examined experimentally and theoretically. In contrast to the noble-gas complexes, for which the calculated intermolecular VZPEs are only $4 \%-11 \%$ of the binding energy $D_{e}$, the contribution from intermolecular VZPE increases for linear molecule adsorbates increases to $10 \%-20 \%$ of $D_{e}$ because of the additional two rotation-type intermolecular vibrations. Experimentally nearly all of the three translation-type $S_{1}$ state intermolecular vibrations were experimentally observed, as well as one of the rotation-type vibrations.

Together with the $D_{0}$ values of other previously measured intermolecular complexes, ${ }^{13,50}$ the $D_{0}$ values of these 1-naphthol.S complexes can serve as benchmarks for testing both highly correlated $a b$ initio calculations and density functional methods, as well as for improving the understanding and modeling of intermolecular interactions.

\section{SUPPLEMENTARY MATERIAL}

See the supplementary material for additional figures, tables of Cartesian coordinates of the studied complexes optimized by the DFT methods and fluorescence lifetime data, as mentioned in the text.

\section{ACKNOWLEDGMENTS}

We thank the Swiss National Science Foundation for financial support (Grant No. 200021E-160404) as well as the Priority Program SPP1807 "Control of London dispersion interactions in molecular chemistry" of the Deutsche Forschungsgemeinschaft.

\section{REFERENCES}

${ }^{1}$ F. London, Z. Phys. 63, 245 (1930).

${ }^{2}$ R. Eisenschitz and F. London, Z. Phys. 60, 491 (1930).

${ }^{3}$ G. C. Maitland, M. Rigby, E. B. Smith, and W. A. Wakeham, Intermolecular Forces: Their Origin and Determination (Clarendon Press, Oxford, 1981).

${ }^{4}$ A. J. Stone, The Theory of Intermolecular Forces, 2nd ed. (Oxford University Press, Oxford, UK, 2013).

${ }^{5}$ P. E. S. Wormer and A. van der Avoird, Chem. Rev. 100, 4109 (2000).

${ }^{6}$ G. R. Desiraju and T. Steiner, The Weak Hydrogen Bond in Structural Chemistry and Biology (Oxford University Press, 2001).

${ }^{7}$ T. Steiner, Angew. Chem., Int. Ed. 41, 48 (2002).

${ }^{8}$ M. Mons, I. Dimicoli, and F. Piuzzi, Int. Rev. Phys. Chem. 21, 101 (2002).

${ }^{9}$ L. Goerigk and S. Grimme, Phys. Chem. Chem. Phys. 13, 6670 (2011).

${ }^{10}$ P. Hobza, Acc. Chem. Res. 45, 663 (2012).

${ }^{11}$ C. D. Sherrill, Acc. Chem. Res. 46, 1020 (2013).

${ }^{12}$ J. P. Wagner and P. Schreiner, Angew. Chem., Int. Ed. 54, 12274 (2015).

${ }^{13}$ J. A. Frey, C. Holzer, W. Klopper, and S. Leutwyler, Chem. Rev. 116, 5614 (2016).

${ }^{14}$ S. Grimme, J. Comput. Chem. 25, 1463 (2004).

${ }^{15}$ S. Grimme, J. Comput. Chem. 27, 1787 (2006).

${ }^{16}$ J.-D. Chai and M. Head-Gordon, Phys. Chem. Chem. Phys. 10, 6615 (2008)

${ }^{17}$ L. Goerigk and S. Grimme, J. Chem. Theory Comput. 7, 291 (2011).

${ }^{18}$ S. Grimme, A. Hansen, J. G. Brandenburg, and C. Bannwarth, Chem. Rev. 116, 5105 (2016)
${ }^{19}$ S. Maity, R. Knochenmuss, C. Holzer, G. Féraud, J. A. Frey, W. Klopper, and S. Leutwyler, J. Chem. Phys. 145, 164304 (2016).

${ }^{20}$ C. Holzer and W. Klopper, Mol. Phys. 115, 2775 (2017).

${ }^{21}$ C. Holzer and W. Klopper, J. Chem. Phys. 147, 181101 (2017).

${ }^{22}$ P. Jurečka, J. Šponer, J. Černy, and P. Hobza, Phys. Chem. Chem. Phys. 8, 1985 (2006).

${ }^{23}$ K. E. Riley, M. Pitoňák, P. Jurečka, and P. Hobza, Chem. Rev. 110, 5023 (2010).

${ }^{24}$ T. Takatani, E. G. Hohenstein, M. Malagoli, M. S. Marshall, and C. D. Sherrill, J. Chem. Phys, 132, 144104 (2010).

${ }^{25}$ R. Podeszwa, K. Patkowski, and K. Szalewicz, Phys. Chem. Chem. Phys. 12, 5974 (2010).

${ }^{26}$ R. A. Mata and M. A. Suhm, Angew. Chem., Int. Ed. 56, 11011 (2017).

${ }^{27}$ S. Grimme, J. Antony, S. Ehrlich, and H. Krieg, J. Chem. Phys. 132, 154104 (2010).

${ }^{28}$ L. Goerigk and S. Grimme, J. Chem. Phys. 132, 184103 (2010).

${ }^{29}$ R. Knochenmuss, R. K. Sinha, and S. Leutwyler, J. Chem. Phys. 148, 134302 (2018).

${ }^{30}$ S. Maity, P. Ottiger, F. A. Balmer, R. Knochenmuss, and S. Leutwyler, J. Chem. Phys. 145, 244314 (2016).

${ }^{31}$ R. Knochenmuss, S. Maity, and S. Leutwyler, CHIMIA Int. J. Chem. 71, 7 (2017).

${ }^{32}$ R. Knochenmuss, S. Maity, F. Balmer, C. Müller, and S. Leutwyler, J. Chem. Phys. 149, 034306 (2018).

${ }^{33}$ T. Bürgi, T. Droz, and S. Leutwyler, J. Chem. Phys. 103, 7228 (1995).

${ }^{34}$ C. Wickleder, D. Henseler, and S. Leutwyler, J. Chem. Phys. 116, 1850 (2002).

${ }^{35}$ R. Knochenmuss, R. K. Sinha, A. Poblotzki, T. Den, and S. Leutwyler, J. Chem. Phys. 149, 204311 (2018).

${ }^{36}$ C. Wickleder, T. Droz, T. Bürgi, and S. Leutwyler, Chem. Phys. Lett. 264, 257 (1997).

${ }^{37}$ T. Droz, T. Bürgi, and S. Leutwyler, J. Chem. Phys. 103, 4035 (1995).

${ }^{38}$ T. Bürgi, T. Droz, and S. Leutwyler, Chem. Phys. Lett. 246, 291 (1995).

${ }^{39}$ H.-L. Dai and R. W. Field, Molecular Dynamics and Spectroscopy by Stimulated Emission Pumping (World Scientific, Singapore, 1995).

${ }^{40}$ M. J. Frisch, G. W. Trucks, H. B. Schlegel, G. E. Scuseria, M. A. Robb, J. R. Cheeseman, G. Scalmani, V. Barone, G. A. Petersson, H. Nakatsuji, X. Li, M. Caricato, A. V. Marenich, J. Bloino, B. G. Janesko, R. Gomperts, B. Mennucci, H. P. Hratchian, J. V. Ortiz, A. F. Izmaylov, J. L. Sonnenberg, D. Williams-Young, F. Ding, F. Lipparini, F. Egidi, J. Goings, B. Peng, A. Petrone, T. Henderson, D. Ranasinghe, V. G. Zakrzewski, J. Gao, N. Rega, G. Zheng, W. Liang, M. Hada, M. Ehara, K. Toyota, R. Fukuda, J. Hasegawa, M. Ishida, T. Nakajima, Y. Honda, O. Kitao, H. Nakai, T. Vreven, K. Throssell, J. A. Montgomery, Jr., J. E. Peralta, F. Ogliaro, M. J. Bearpark, J. J. Heyd, E. N. Brothers, K. N. Kudin, V. N. Staroverov, T. A. Keith, R. Kobayashi, J. Normand, K. Raghavachari, A. P. Rendell, J. C. Burant, S. S. Iyengar, J. Tomasi, M. Cossi, J. M. Millam, M. Klene, C. Adamo, R. Cammi, J. W. Ochterski, R. L. Martin, K. Morokuma, O. Farkas, J. B. Foresman, and D. J. Fox, gaussian 16, Revision A.03, Gaussian, Inc., Wallingford, CT, 2016.

${ }^{41}$ T. Bürgi, T. Droz, and S. Leutwyler, Chem. Phys. Lett. 225, 351 (1994).

${ }^{42}$ M. Zierhut, W. Roth, S. Dümmler, and I. Fischer, Chem. Phys. 305, 123 (2004).

${ }^{43}$ M. Schäfer, C. Kang, and D. Pratt, J. Phys. Chem. A 107, 10753 (2003).

${ }^{44}$ P. R. Bunker, J. W. C. Johns, A. R. W. Mckellar, and C. Dilauro, J. Mol. Spectrosc. 162, 142 (1993).

${ }^{45}$ U. Dahmen, H. Dreizler, and W. Stahl, Ber. Bunges. Phys. Chem. 99, 434 (1995).

${ }^{46}$ J. N. Oliaee, M. Dehghany, M. Afshari, N. Moazzen-Ahmadi, and A. R. W. McKellar, J. Chem. Phys. 131, 161105 (2009).

${ }^{47}$ M. Dehghany, J. N. Oliaee, M. Afshari, N. Moazzen-Ahmadi, and A. R. W. McKellar, J. Chem. Phys. 132, 194303 (2010).

${ }^{48}$ CRC Handbook of Chemistry and Physics, 84 th ed., edited by D. R. Lide (CRC Press, Boca Raton, FL, 2004).

${ }^{49}$ P. M. Felker and A. H. Zewail, "Molecular structures from ultrafast coherence spectroscopy," in Femtosecond Chemistry, edited by J. Manz and L. Wöste (VCH, Weinheim, 1995), Vol. I, Chap. 5. 
${ }^{50}$ S. Haldar, R. Gnanasekaran, and P. Hobza, Phys. Chem. Chem. Phys. 17, 26645 (2015).

${ }^{51}$ G. L. D. Ritchie, J. N. Watson, and R. I. Keir, Chem. Phys. Lett. 370, 376 (2003).

${ }^{52}$ S. Corian, A. Halkier, D. Jonsson, J. Gauss, A. Rizzo, and O. Christiansen, J. Chem. Phys. 118, 7329 (2003).

${ }^{53}$ N. Chetty and V. W. Couling, J. Chem. Phys. 134, 164307 (2011).

${ }^{54}$ J. N. Watson, I. E. Craven, and G. L. D. Ritchie, Chem. Phys. Lett. 274, 1 (1997).

${ }^{55} \mathrm{M}$. Chetty and V. W. Couling, J. Chem. Phys. 134, 144307 (2011).
${ }^{56}$ R. I. Keir, D. W. Lamb, G. L. D. Ritchie, and J. N. Watson, Chem. Phys. Lett. 279, 22 (1997).

${ }^{57}$ N. Chetty and V. W. Couling, Mol. Phys. 109, 655 (2011).

${ }^{58}$ G. L. D. Ritchie and J. N. Watson, Chem. Phys. Lett. 322, 143 (2000).

${ }^{59}$ M. H. Coonan, I. E. Craven, M. R. Hesling, G. L. D. Ritchie, and M. A. Spackman, J. Phys. Chem. 96, 7301 (1992).

${ }^{60}$ A. J. Russell and M. A. Spackman, Mol. Phys. 98, 855 (2000).

${ }^{61}$ W. Majer, P. Lutzmann, and W. Hüttner, Mol. Phys. 83, 567 (1994). 